\title{
Hypoxia induces triglycerides accumulation in prostate cancer cells and extracellular vesicles supporting growth and invasiveness following reoxygenation
}

\author{
Isabel R. Schlaepfer ${ }^{1, *}$, Dhanya K. Nambiar ${ }^{2,3, *}$, Anand Ramteke ${ }^{2,4, *}$, Rahul Kumar ${ }^{2}$, \\ Deepanshi Dhar ${ }^{2}$, Chapla Agarwal2,5, Bryan Bergman ${ }^{6}$, Michael Graner7, Paul \\ Maroni $^{8}$, Rana P. Singh ${ }^{3}$, Rajesh Agarwal ${ }^{2,5}$ and Gagan Deep ${ }^{2,5}$ \\ ${ }^{1}$ Division of Medical Oncology, Department of Medicine, University of Colorado Denver, Aurora, Colorado, USA \\ ${ }^{2}$ Department of Pharmaceutical Sciences, Skaggs School of Pharmacy and Pharmaceutical Sciences, University of Colorado \\ Denver, Aurora, Colorado, USA \\ ${ }^{3}$ Cancer Biology Laboratory, School of Life Sciences, Jawaharlal Nehru University, New Delhi, India \\ ${ }^{4}$ Department of Molecular Biology and Biotechnology, Tezpur University, Tezpur, India \\ ${ }^{5}$ University of Colorado Cancer Center, University of Colorado Denver, Aurora, Colorado, USA \\ ${ }^{6}$ Division of Endocrinology, Metabolism and Diabetes, University of Colorado Denver, Aurora, Colorado, USA \\ 7 Department of Neurosurgery, University of Colorado Denver, Aurora, Colorado, USA \\ 8 Department of Surgery, University of Colorado Denver, Aurora, Colorado, USA \\ * These authors have contributed equally to this work \\ Correspondence to: Gagan Deep, email: Gagan.deep@ucdenver.edu
}

Rajesh Agarwal, email: Rajesh.Agarwal@ucdenver.edu

Keywords: hypoxia, extracellular vesicle, prostate cancer, lipids, $\beta$-oxidation

Received: January 30, $2015 \quad$ Accepted: May 22, $2015 \quad$ Published: June15,2015

This is an open-access article distributed under the terms of the Creative Commons Attribution License, which permits unrestricted use, distribution, and reproduction in any medium, provided the original author and source are credited.

\section{ABSTRACT}

Hypoxia is an independent prognostic indicator of poor outcome in several malignancies. However, precise mechanism through which hypoxia promotes disease aggressiveness is still unclear. Here, we report that under hypoxia $\left(1 \% \mathrm{O}_{2}\right)$, human prostate cancer (PCA) cells, and extracellular vesicles (EVs) released by these cells, are significantly enriched in triglycerides due to the activation of lipogenesis-related enzymes and signaling molecules. This is likely a survival response to hypoxic stress as accumulated lipids could support growth following reoxygenation. Consistent with this, significantly higher proliferation was observed in hypoxic PCA cells following reoxygenation associated with rapid use of accumulated lipids. Importantly, lipid utilization inhibition by CPT1 inhibitor etomoxir and shRNA-mediated CPT1-knockdown significantly compromised hypoxic PCA cell proliferation following reoxygenation. Furthermore, COX2 inhibitor celecoxib strongly reduced growth and invasiveness following hypoxic PCA cells reoxygenation, and inhibited invasiveness induced by hypoxic PCA EVs. This establishes a role for COX2 enzymatic products in the enhanced PCA growth and invasiveness. Importantly, concentration and loading of EVs secreted by PCA cells were significantly compromised under delipidized serum condition and by lipogenesis inhibitors (fatostatin and silibinin). Overall, present study highlights the biological significance of lipid accumulation in hypoxic PCA cells and its therapeutic relevance in PCA.

\section{INTRODUCTION}

Prostate cancer (PCA) is the most common non- cutaneous cancer in men. According to the American Cancer Society reports, 233,000 new cases and 29,480 deaths from PCA were estimated in the United States in 
2014 [1]. Several studies have shown that low oxygen in the tumor microenvironment, known as hypoxia, determines disease aggressiveness, and is an independent prognostic indicator of poor outcome in PCA as well as in several other malignancies [2-6]. Hypoxic environment within the prostate is considered responsible for the generation of secondary mutations in the genome, leading to aggressive and lethal PCA [7]. Hypoxia is also considered the first major challenge encountered by the growing mass of neoplastic cells, as cancer cells in hypoxic areas are surrounded by metabolic waste, acidic $\mathrm{pH}$ and necrotic cells $[8,9]$. To overcome these hostile conditions, tumor cells activate transcriptional machinery (e.g. hypoxia inducible factors [HIFs]) leading to neoangiogenesis and altered anaerobic metabolism; however, the precise mechanism through which hypoxic conditions promote growth and metastasis are still not well defined.

Recent literature has established a critical role for nano-sized vesicles in inter-cellular communication, primary tumor growth, angiogenesis, pre-metastatic niches preparation, metastasis, drug resistance, immunosuppression and disease relapse [10-13]. In the past, ambiguity about the nomenclature of these vesicles resulted in different terms such as, exosomes, microvesicles, ectosomes, shedding vesicles, or microparticles. It is now agreed to label these vesicles as extracellular vesicles (EVs), which are further subcategorized into exosomes and microvesicles mainly based upon their site of origin; vesicles formed in multi-vesicular bodies (MVBs) of the endosomal system, but released extracellular, are termed exosomes $(\sim$ size $50-150 \mathrm{~nm})$, while vesicles budding directly from the membranes are named microvesicles ( $\sim$ size 100-1000 nm). Recent studies have clearly established that hypoxic cancer cells secrete copious amounts of EVs, which promote tumor growth and progression [12, 14]. King et al. showed that breast cancer cells secrete higher amount of exosomes under hypoxic condition in a HIF1 $\alpha$-dependent manner [14]. Under hypoxic conditions, adipocyte-released exosomes promoted lipogenesis in 3T3-L1 recipient cells [15]. Furthermore, exosomes secreted by hypoxic cancer cells promote angiogenesis via cargo loaded in these exosomes such as miRNAs $[10,11]$. Besides exosomes, hypoxia significantly enhanced the microvesicles biogenesis in a HIF $1 \alpha$ - and RAB22A GTPase-dependent manner, and promoted the formation of focal adhesions, invasiveness and metastasis in naïve breast cancer cells [12]. We have recently reported that EVs secreted by PCA cells under hypoxic conditions induce epithelial-to-mesenchymal transition (EMT), invasiveness and stemness in naïve PCA cells; they also promote cancer-associated fibroblast (CAF) phenotype in naïve normal prostate fibroblasts [2]. We have also reported that hypoxic PCA EVs are loaded with unique proteins with higher expression of canonical markers, MMPs, and signaling molecules compared to normoxic PCA EVs [2]; however, little is known about the effect of hypoxia on lipid levels in PCA cells as well as their EVs.

In a recent study, Llorente et al. reported that PCA cells exhibit a strong ( $>8$-fold) enrichment of lipids in exosomes [16]. The majority of the lipid classes studied in exosomes includes phospholipids, cholesterol and sphingomyelin. However, less attention has been focused on the triglycerides, a form of neutral lipid that is abundant in lipid droplets inside the cells [17]. Triglycerides have been historically regarded as inert lipid depots that accumulate in the cytoplasm of most cells. More recently, the dynamics of lipid droplet triglycerides has been revamped with several studies suggesting that triglyceride stores are dynamic and provide survival benefits to normal and cancer cells [18-20]. In this regard, the present study examined the biological significance of lipid accumulation in PCA cells under hypoxic conditions, as well as the role of EVs as bioactive lipid carriers. Our results show that lipid accumulation under hypoxia supports PCA growth and invasiveness following reoxygenation, and hypoxic PCA EVs loaded with bioactive lipids also enhance the invasiveness of naïve PCA cells. Moreover, these results suggest that EV biogenesis and cargo are dependent upon lipid availability and de novo lipogenesis in PCA cells.

\section{RESULTS}

\section{Hypoxia influences the fatty acid composition of PCA cells and their EVs}

LNCaP cells were exposed to normoxic $\left(21 \% \mathrm{O}_{2}\right)$ or hypoxic $\left(1 \% \mathrm{O}_{2}\right)$ conditions for $48 \mathrm{hrs}$. Thereafter, cells and EVs were collected and subjected to lipid isolation and analysis by GC-MS. We examined the fatty acid composition of the phospholipid, triglyceride and diacylglycerol lipid fractions. Table 1A shows the fatty acid composition of phospholipids, triglycerides and diacylglycerols from LNCaP cells and their respective EVs grown under normoxic conditions. Four replicates were used for each sample, and the order of the fatty acids is based on their carbon chain length from top to bottom. Myristic acid (14:0) and palmitic acid (16:0) were significantly decreased in the phospholipids of normoxic LNCaP cells EVs $(p<0.05)$, while stearic acid (18:0) was increased by $\sim 2$ fold $(p<0.01)$ and accounts for the increased saturation index of EVs compared to LNCaP cell phospholipids ( $70 \%$ vs. $56.7 \%, p<0.01)$. We also observed a significant decrease in oleic acid (18:1) and an increase in linoleic acid (18:2) in the phospholipids of EVs from normoxic LNCaP cells (Table 1A). These data are in agreement with previous studies where palmitic, stearic and oleic acids were the most abundant fatty acids in normoxic exosomes from rodent mast cells [21] .

The center column in Table 1A contains the 
Table 1: Lipid content in PCA cells and EVs under normoxic and hypoxic conditions. LNCaP cells were cultured under normoxic and hypoxic conditions for $48 \mathrm{hrs}$. At the end, cells and EVs were collected and analyzed by GC-MS for fatty acid composition $(\% \mathrm{~mol})$ of phospholipid, triglycerides and diacylglyerols. In each case, 4 biological replicates were analyzed and data are presented as mean \pm SD. \#, $p \leq 0.01 ; \$, p \leq 0.05$

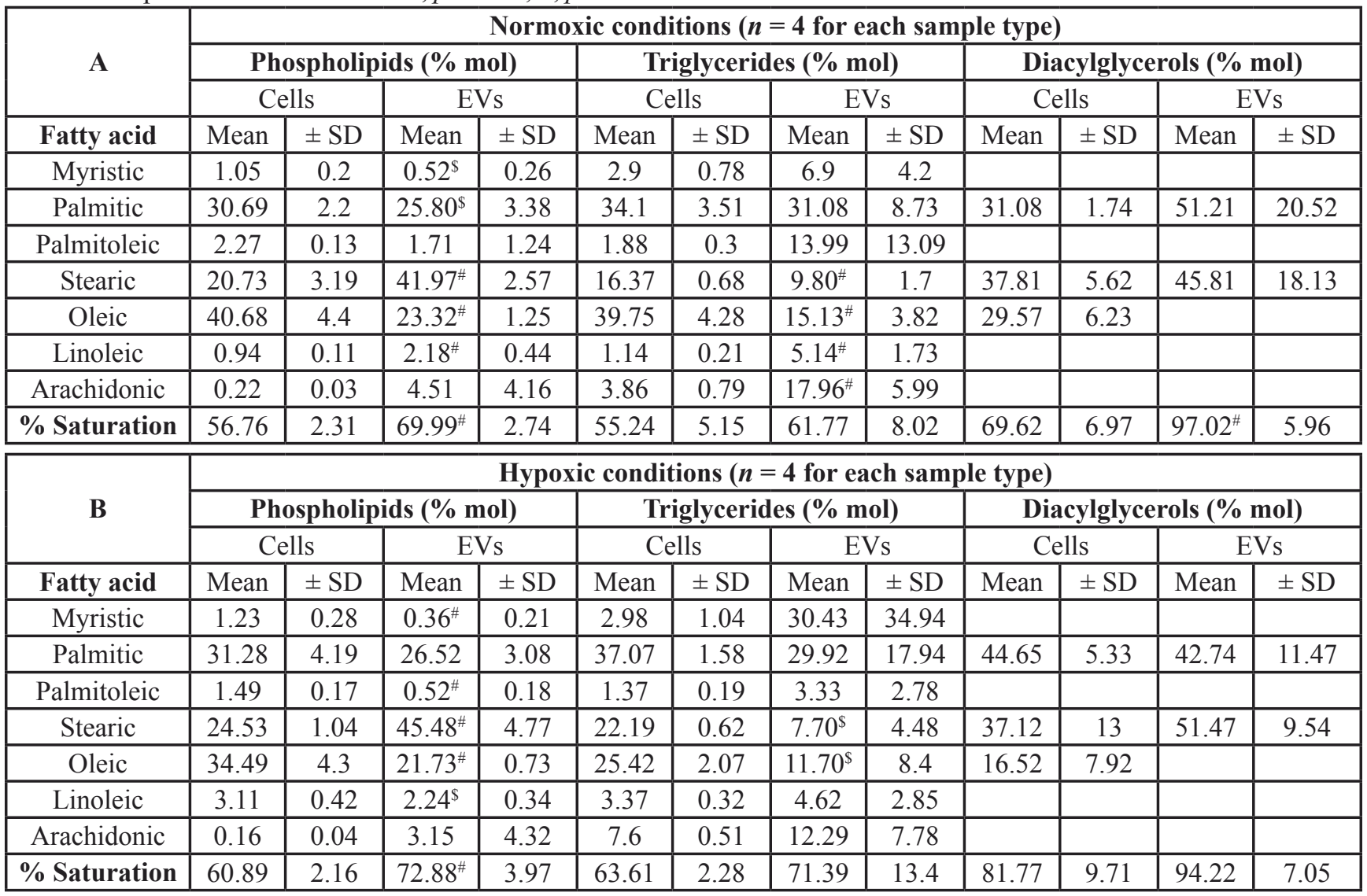

triglyceride information. We found that stearic and oleic acids were significantly decreased in EVs triglycerides compared to the parental cells $(p<0.01)$. Interestingly, the omega-6 fatty acids linoleic acid (18:2) and arachidonic acid (20:4) were strongly represented in the EVs triglycerides $(\sim 5$-fold, $p<0.01)$ underscoring the role of EVs as bioactive lipid carriers. The diacylglycerol fractions of LNCaP cells and EVs did not show any significant changes in fatty acid composition although we only observed the saturated palmitic (16:0) and stearic (18:0) species in EVs (Table 1A).

Table 1B shows the fatty acid composition from LNCaP cells and their respective EVs grown under hypoxic conditions. The percentage of fatty acid saturation in phospholipids was significantly increased in EVs compared to their parental cells ( $\sim 73 \%$ vs. $\sim 61 \%$ $p<0.01)$, likely driven by a significant 2 -fold increase in stearic acid (saturated, $p<0.01$ ) and a concomitant decrease in oleic acid (monounsaturated fatty acid, $p<$ 0.01). Exposure to hypoxia did not further significantly increase the saturation index of EVs but it did so in the cell membrane phospholipids ( $57 \%$ saturation in normoxic LNCaP cells vs. $61 \%$ saturation in hypoxic LNCaP cells, $p<0.01)$. The triglyceride composition in hypoxic conditions showed strong variability in our samples and it was not possible to detect significant changes in fatty acid composition of the EVs, except for stearic and oleic acid species that were significantly reduced $(p<0.05)$. Similar to normoxic condition, we did not observe any significant change in diacylglycerol fractions of LNCaP cells and EVs under hypoxic condition.

Further examination of the fatty acid concentration of the triglycerides provided additional information about the changes in the cells and their respective EVs. Figure 1A shows fatty acid composition of triglycerides isolated from EVs of LNCaP cells grown in normoxic and hypoxic conditions. Significant increases in palmitic, stearic and linoleic acids were observed in $\mathrm{EVs}^{\text {Hypoxic }}$ compared to $\mathrm{EVS}^{\text {Normoxic }}$ ( 2-fold, $\left.p<0.01\right)$. Overall, a 3-fold increase in triglycerides was observed under hypoxia when compared to normoxia $(p<0.05)$ (Figure 1B). In LNCaP cells, myristic, palmitic and stearic fatty acids (all saturated fatty acids) were significantly increased under hypoxia compared to normoxia (Figure 1C). Of note, essential linoleic acid and its derivative arachidonic acid were both significantly increased in the triglycerides of hypoxic LNCaP cells (4.5-fold and 3-fold, respectively; $p<0.05$ ) (Figure 1C). These results are important since both fatty acids are strongly implicated in inflammation and malignant tumor growth. Similar to $\mathrm{EVs}^{\mathrm{Hypoxic}}$, LNCaP 
cells also showed higher triglycerides level under hypoxic condition, but the changes were not significant (Figure 1D).

\section{Altered signaling and metabolic enzymes expression in LNCaP cells exposed to hypoxia}

In order to investigate the molecular changes in LNCaP cells exposed to hypoxia, we collected cell lysates following 1, 3, 6 and $72 \mathrm{hrs}$ of hypoxia exposure, and at 1 and 72 hrs of normoxia exposure (first and last lanes, Figure 2). These lysates were used to interrogate expression of signaling molecules and enzymes involved in lipid and glucose metabolism. Figure 2A shows the strong expression levels of HIF $1 \alpha$ within $3 \mathrm{hrs}$ of exposure to hypoxia. Phosphorylation of mTOR (mammalian target of rapamycin) was also increased by $3 \mathrm{hrs}$, concomitant with the Akt activation (Figure 2A). The phosphorylation of mTOR decreased rapidly by $6 \mathrm{hrs}$ in hypoxia and no expression was observed at 72 hrs. This could be partly due to longer incubation time of the cells that depletes the media of nutrients, since cells grown in normoxic conditions for $72 \mathrm{hrs}$ (last lane) also did not show the activation of mTOR (phosphorylation at Serine 2448) (Figure 2A). However, activation of Akt (Ser 473) was still observed after $72 \mathrm{hrs}$ of hypoxia (Figure 2A).

Since inactivation of mTOR was observed at later time-point under hypoxia, we then examined the expression and activation status of the cellular fuel sensor AMPK (AMP-activated protein kinase) and one of its downstream targets- ACC (acetyl Co-A carboxylase). As shown in Figure 2B, AMPK was activated at 72 hrs timepoint under hypoxia. This is in accordance with earlier reports, which showed that hypoxia induces AMPK levels
A

\begin{tabular}{|l|c|c|c|c|}
\hline \multirow{2}{*}{} & \multicolumn{4}{|c|}{ EVs (n=4) } \\
\cline { 2 - 5 } & \multicolumn{3}{|c|}{ Triglycerides ( $\mu$ /100Kcells) } \\
\cline { 2 - 5 } & \multicolumn{2}{|c|}{ Normoxic } & \multicolumn{2}{c|}{ Hypoxic } \\
\hline \multirow{2}{*}{ Fatty acid } & Mean & \pm SD & Mean & \pm SD \\
\hline Myristic & 0.0009 & 0.0012 & 0.0123 & 0.0167 \\
\hline Palmitic & 0.0027 & 0.001 & $0.0071^{\$}$ & 0.0029 \\
\hline Palmitoleic & 0.0018 & 0.002 & 0.0009 & 0.001 \\
\hline Stearic & 0.0006 & 0 & $0.0018^{\#}$ & 0.0004 \\
\hline Oleic & 0.0014 & 0.0009 & 0.0027 & 0.0011 \\
\hline Linoleic & 0.0005 & 0.0002 & $0.0011^{\$}$ & 0.0003 \\
\hline Arachidonic & 0.0019 & 0.0019 & 0.0034 & 0.0027 \\
\hline
\end{tabular}

C

\begin{tabular}{|c|c|c|c|c|}
\hline \multirow[b]{4}{*}{ Fatty : } & \multicolumn{4}{|c|}{ Cells $(n=4)$} \\
\hline & \multicolumn{4}{|c|}{ Triglycerides ( $\mu \mathrm{g} / 100 \mathrm{~K}$ cells) } \\
\hline & \multicolumn{2}{|c|}{ Normoxic } & \multicolumn{2}{|c|}{ Hypoxic } \\
\hline & Mean & $\pm \mathrm{SD}$ & Mean & $\pm \mathrm{SD}$ \\
\hline Myristic & 0.017 & 0.004 & $0.024^{5}$ & 0.005 \\
\hline Palmitic & 0.201 & 0.019 & $0.270^{5}$ & 0.036 \\
\hline Palmitoleic & 0.011 & 0.002 & 0.013 & 0.008 \\
\hline Stearic & 0.097 & 0.009 & $0.158^{\#}$ & 0.023 \\
\hline Oleic & 0.236 & 0.042 & 0.238 & 0.13 \\
\hline Linoleic & 0.007 & 0.002 & $0.030^{\#}$ & 0.011 \\
\hline Arachidonic & 0.023 & 0.007 & $0.070^{5}$ & 0.035 \\
\hline
\end{tabular}

B
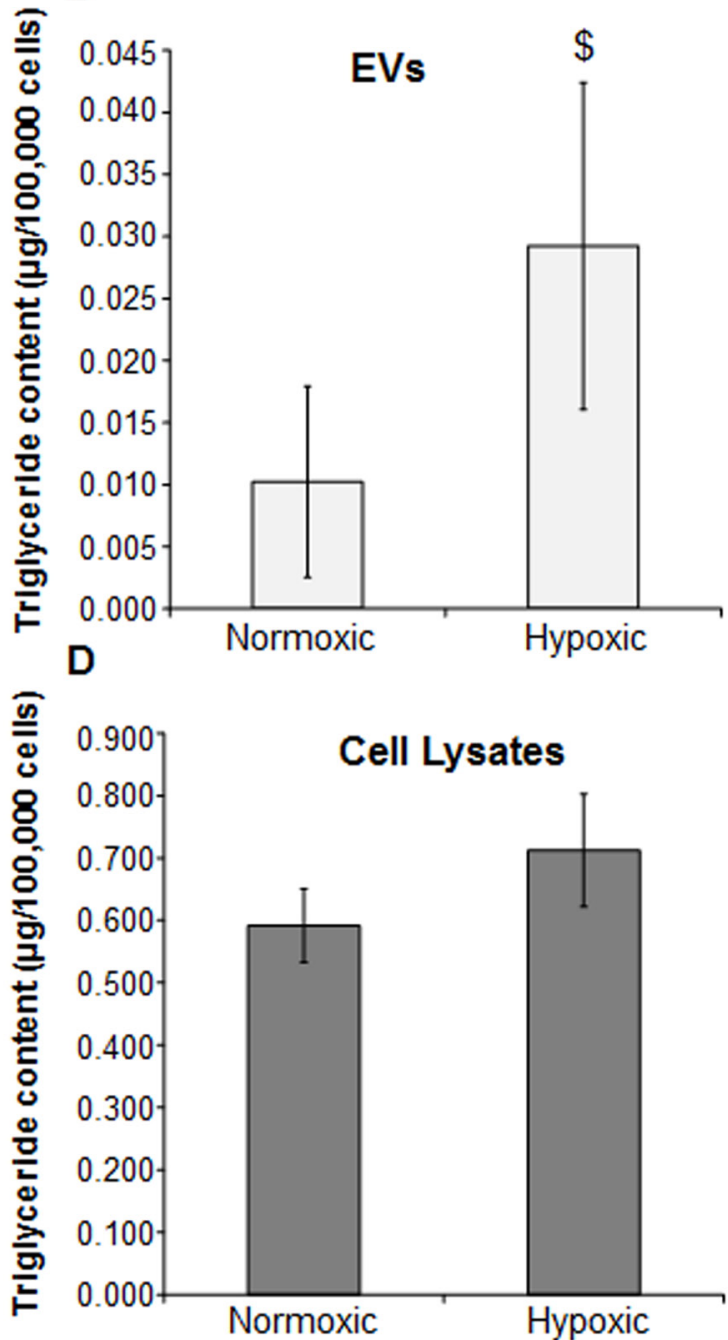

Figure 1: Hypoxia induces triglyceride accumulation in LNCaP cells and EVs. A.-D. LNCaP cells were cultured under normoxic $\left(21 \% \mathrm{O}_{2}\right)$ and hypoxic $\left(1 \% \mathrm{O}_{2}\right)$ conditions for $48 \mathrm{hrs}$. At the end, EVs and cells were collected and analyzed for fatty acid constitution of triglycerides as well as triglyceride content (bar diagrams) and presented as $\mu \mathrm{g} / 100 \mathrm{~K}$ cells. In each case, 4 samples were processed and data are presented as mean $\pm \mathrm{SD}$. \#, $p \leq 0.01 ; \$, p \leq 0.05$. 
very late $[22,23]$. This could be explained by the fact that AMPK activation is dependent on the AMP/ATP ratio, and in the initial stages of hypoxia, cellular ATP levels are maintained via enhanced glycolysis. Hence, AMPK becomes active only at late stages. The ACC enzyme uses glucose carbons to generate malonyl-coA that leads to de novo lipid synthesis. Phosphorylation of ACC at Serine
79 by AMPK results in inactivation of the enzyme. We observed an increase in ACC phosphorylation along with higher total ACC protein ( 2-fold) under hypoxia (Figure 2B), suggesting high carboxylase activity at 6 hrs leading to fatty acid synthesis.

Figure 2C shows the expression of lipid synthesis enzymes (ATP-citrate lyase, acetyl-CoA synthetase and



Figure 2: Hypoxia activates signaling cascades involved in lipid synthesis. $\mathrm{LNCaP}$ cells were exposed to hypoxia $\left(1 \% \mathrm{O}_{2}\right)$ and cell lysates were prepared after 1,3,6 and $72 \mathrm{hrs}$. Cells cultured under normoxic condition $\left(21 \% \mathrm{O}_{2}\right)$ at 1 and $72 \mathrm{hrs}$ served as relevant controls. Cell lysates were prepared and analyzed by immunoblotting for the expression of various A. signaling molecules, B.-C. lipogenesis regulators, and $\mathbf{D}$. glucose metabolism enzymes. Membranes were stripped and re-probed for $\alpha$-tubulin and representative blots are shown. Densitometry data presented below the bands are 'fold change' as compared with respective normoxic control after normalization with respective loading control ( $\alpha$-tubulin). N: Normoxic; ND: Not detectable. 
fatty acid synthase) and post-synthesis enzymes (acyl CoA synthase ligase, and steroyl-CoA-desaturase1) under hypoxic condition. The ATP-citrate lyase (ACLY) enzyme is activated by phosphorylation at Serine 455 by Akt. Activation of the ACLY enzyme at 3, 6 and 72 hrs parallels the activation of Akt in Figure 2A. The fatty acid synthase enzyme (FASN) expression increased under hypoxia but was strongly decreased by $72 \mathrm{hrs}$ (Figure 2C), matching the inactivation of ACC by AMPK (Figure 2B). Furthermore, the enzyme that activates newly synthesized fatty acids, acyl CoA synthase ligase (ACSL) also showed an increase at early time points. This is relevant since the newly synthesized fatty acids need to be processed by ACSL in order to be directed to membrane phospholipids or triglycerides. Note the low expression of acetyl-CoA synthetase (AceCS1) in hypoxia, suggesting that acetate is not the main substrate for the lipid synthesis. Another enzyme involved in lipid synthesis is steroyl-CoA desaturase (SCD1), which is involved in the generation of monounsaturated fatty acids (like oleic and palmitoleic acid) [24]. However, little is known about the mechanisms of SCD1 action in PCA cells under hypoxia. We observed increased expression of SCD1 in hypoxic cells from 1 to $72 \mathrm{hrs}$ (Figure 2C), suggesting a protective response, since accumulation of saturated lipids by inhibition of SCD1 promotes cell death [25]. Overall, these molecular results add strength to the lipogenic phenotype of PCA cells grown under hypoxic conditions.

Activation of HIF $1 \alpha$ by hypoxia is known to be associated with a glycolytic phenotype in many cancer cells, with a substantial increase in glucose uptake. We next examined the expression of hexokinases and pyruvate kinase 2 (muscle isoform or PKM2) as surrogates of increased glucose uptake in the hypoxic LNCaP cells. Figure 2D shows that both hexokinases (I and II) are upregulated under hypoxia. Hexokinase is most abundant in cancer cells and is a direct target of HIF $1 \alpha$ protein, a result that correlates with the HIF $1 \alpha$ activation shown in Figure 2A. Pyruvate kinase 2 is also a master regulator of metabolism in cancer cells [26]. It is upregulated by HIF $1 \alpha$ and modulates the production of lactate and glycolytic intermediates necessary for lipid and nucleic acid synthesis. A gradual increase in PKM2 between 3 and $72 \mathrm{hrs}$ was observed in hypoxic LNCaP cells (Figure 2D). These results suggest that increased glucose uptake in hypoxia promotes de novo lipogenesis in PCA cells mediated by ACLY, ACC and FASN enzymes (Figure 2C).

\section{Hypoxia-induced lipid accumulation promotes proliferation in PCA cells following reoxygenation}

We next examined the role of lipid stores on PCA growth following reoxygenation. PCA cells were cultured under hypoxic conditions for $48 \mathrm{hrs}$ (labeled as $0 \mathrm{hr}$ ), and thereafter, maintained under continuous hypoxia (for 24-72 hrs) or returned to normoxia (for 24-72 hrs). Throughout, cell proliferation rate was measured by trypan blue assay, and correlated with cellular lipid level by staining cells with Oil red O (ORO) that mainly stains cellular neutral triglycerides and cholesteryl esters. As shown in Figure 3A and 3B, at each timepoint, there was significantly higher lipid accumulation in hypoxic LNCaP cells compared with normoxic cells. Following reoxygenation, LNCaP cells (labeled 'HypoxicNormoxic') showed a consistent decrease in accumulated lipid level compared with hypoxic cells (Figure 3A and 3B). We speculated that under hypoxic stress, PCA cells store energy in the form of lipid droplets, which would be burned when a favorable environment $\left(\mathrm{O}_{2}\right)$ is available. As expected, under hypoxic conditions, LNCaP cell growth was significantly inhibited and higher cell death was observed at most of the time-points (Figure 3C and 3D). However, following reoxygenation, $\mathrm{LNCaP}$ cell proliferation increased steadily (Figure 3C). Interestingly, growth rate of hypoxic-normoxic cells was even higher than normoxic LNCaP cells (Figure 3C). Regarding cell death, at $72 \mathrm{hrs}$ time point, the hypoxic-normoxic cells showed $38 \%$ cell death, while the normoxic and hypoxic controls showed 52 and $48 \%$ cell respectively (Figure 3D). Notably, the increase in cell number in hypoxic-normoxic group correlated inversely to the lipid content.

In $\mathrm{C} 4-2 \mathrm{~B}$ (an androgen-independent $\mathrm{LNCaP}$ subline) and DU145 PCA cells, we observed rather similar responses to hypoxia in terms of higher neutral lipid accumulation as well as proliferation following reoxygenation (Figure 4 and Figure 5). However, C42B cells took much longer time than $\mathrm{LNCaP}$ cells to utilize the lipid reserves and grow aggressively (Figure $4 \mathrm{~A}$ and $4 \mathrm{~B}$ ). We found that after $24 \mathrm{hrs}$ of shifting the cells to normoxia, the lipid content was reduced by $23 \%$, but by the end of $48 \mathrm{hrs}$, the lipid content was decreased by $67 \%$ (Figure 4B). The cell number also increased significantly especially at the end of $72 \mathrm{hrs}$, but surprisingly, we observed relatively higher death in reoxygenated cells compared with hypoxic cells (Figure 4C and 4D). A similar trend was observed in DU145 cells, with maximum decrease in lipid accumulation at $72 \mathrm{hrs}$ following reoxygenation (Figure 5A and 5B). DU145 cells in normoxic condition grew by 2.4 times between 24 and $72 \mathrm{hrs}$ time-points; in hypoxic condition, we did not see any significant growth; however following reoxygenation, the cells grew by 2.7 times between 24 and $72 \mathrm{hrs} \mathrm{time-}$ points (Figure 5C and 5D). The percentage of cell death also showed a significant decrease in hypoxic-normoxic condition compared with normoxia or hypoxia at $72 \mathrm{hrs}$ after reoxygenation (Figure 5D). 

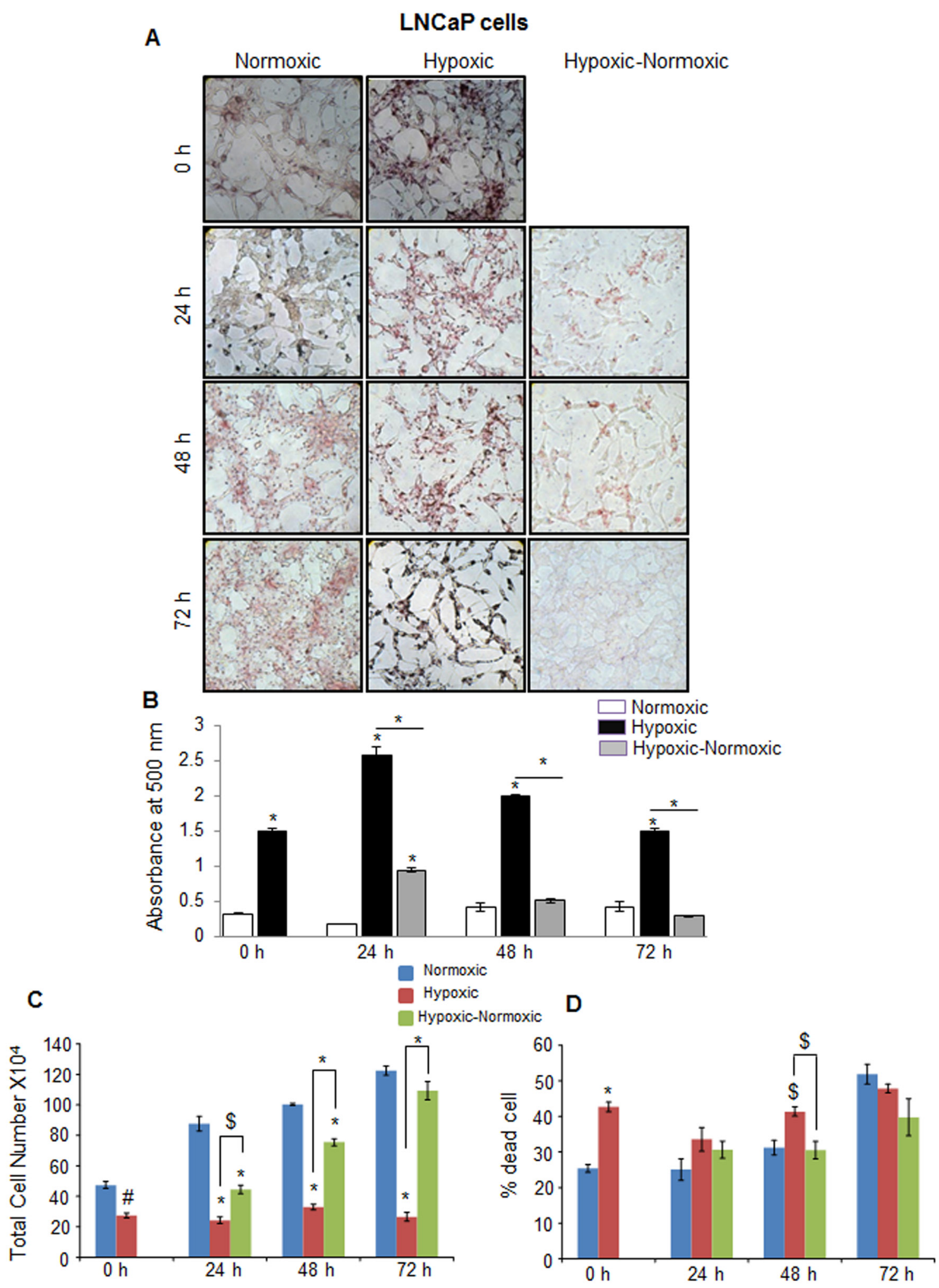

Figure 3: Hypoxia induces lipid accumulation and promotes proliferation following reoxygenation in prostate cancer LNCaP cells. LNCaP cells were seeded at 50,000 cells/ well in a 6 well plate. After $36 \mathrm{hrs,} \mathrm{media} \mathrm{was} \mathrm{changed} \mathrm{and} \mathrm{cells} \mathrm{were} \mathrm{either}$ transferred to hypoxia chamber $\left(1 \% \mathrm{O}_{2}\right)$ or continued under normoxia $\left(21 \% \mathrm{O}_{2}\right)$. After $48 \mathrm{hrs}$, one set of hypoxic plates was transferred to normoxia and maintained in normoxic conditions for 24,48 and $72 \mathrm{hrs,} \mathrm{while} \mathrm{another} \mathrm{set} \mathrm{remained} \mathrm{under} \mathrm{hypoxia.} \mathrm{A.-B.} \mathrm{After} \mathrm{completing}$ the respective time periods, cells were fixed with $10 \%$ formaldehyde and stained with ORO. Representative pictures (at 200X) for ORO staining are shown. Lipid content quantitation was carried out by dye elution using isopropanol, and absorbance was measured by spectrophotometer at $500 \mathrm{~nm}$. C.-D. At every time-point, total cell number and dead cell percentage were also measured. *, $p \leq 0.001$; \#, $p \leq 0.01 ; \$, p \leq 0.05$. 
A

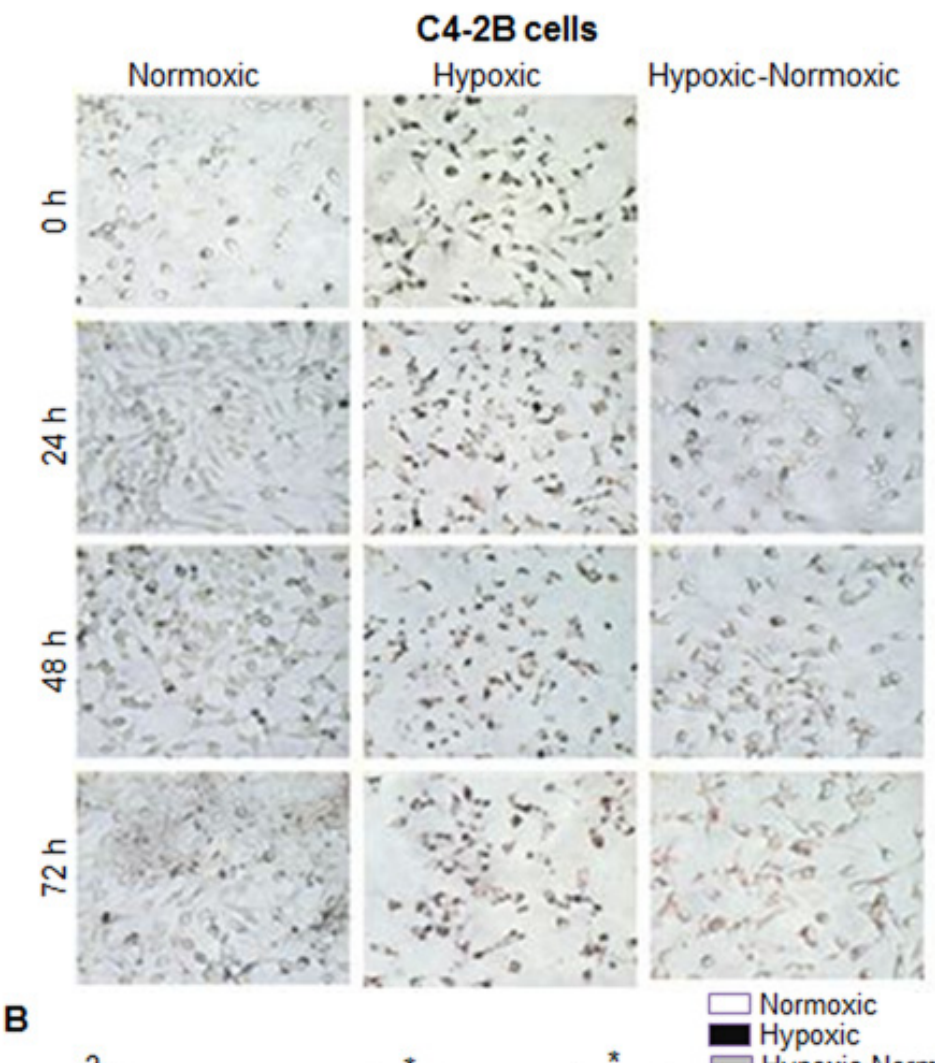

B
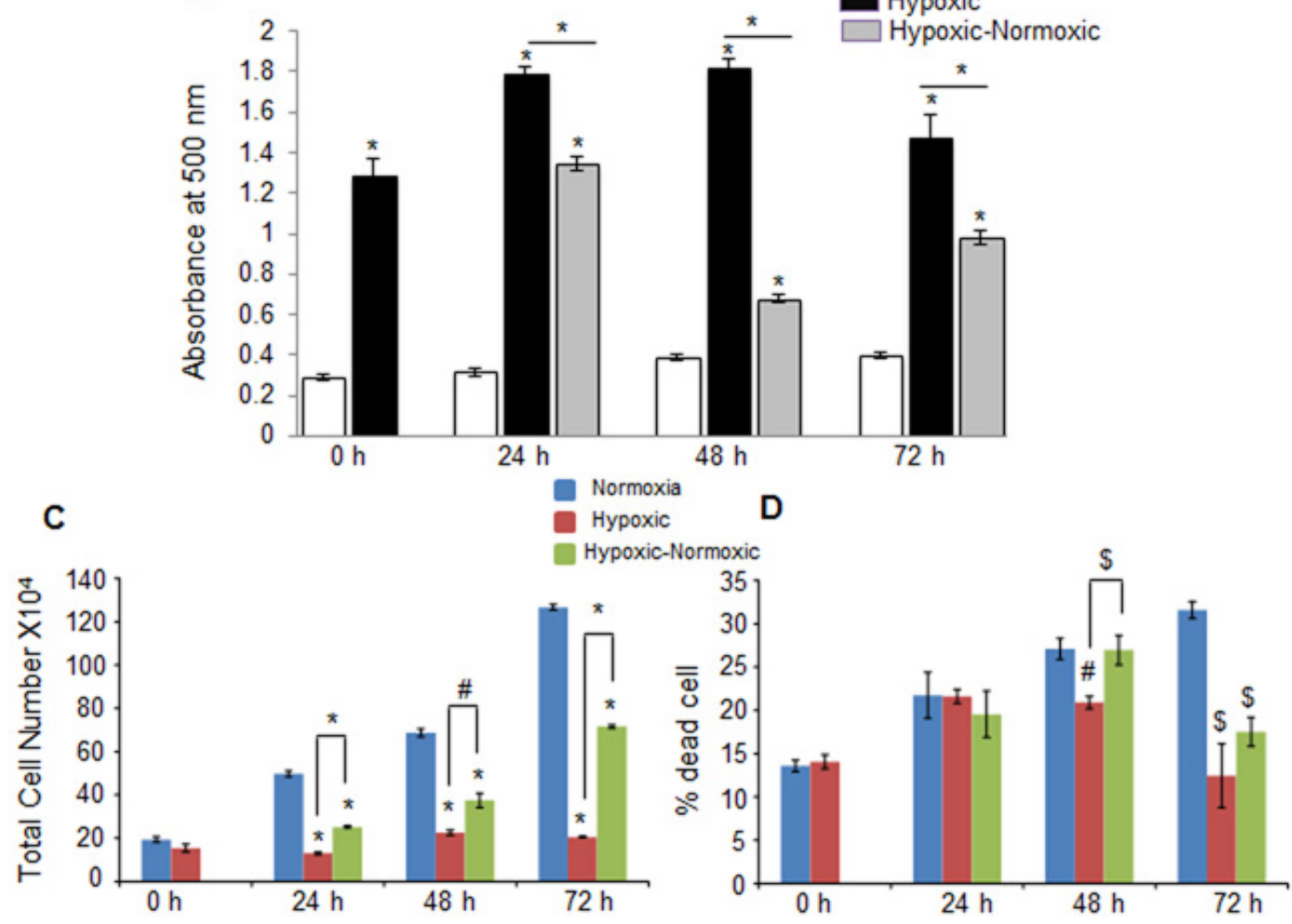

Figure 4: Hypoxia induces lipid accumulation and promotes proliferation following reoxygenation in prostate cancer C4-2B cells. C4-2B cells were seeded at 50,000 cells/ well in a 6 well plate. After $36 \mathrm{hrs,} \mathrm{media} \mathrm{was} \mathrm{changed} \mathrm{and} \mathrm{cells} \mathrm{were} \mathrm{either}$ transferred to hypoxia chamber $\left(1 \% \mathrm{O}_{2}\right)$ or continued under normoxia $\left(21 \% \mathrm{O}_{2}\right)$. After $48 \mathrm{hrs}$, one set of hypoxic plates was transferred to normoxia and maintained in normoxic conditions for 24,48 and $72 \mathrm{hrs,} \mathrm{while} \mathrm{another} \mathrm{set} \mathrm{remained} \mathrm{under} \mathrm{hypoxia.} \mathrm{A.-B.} \mathrm{After} \mathrm{completing}$ the respective time periods; cells were fixed with $10 \%$ formaldehyde and stained with ORO. Representative pictures (at 200X) for ORO staining are shown. Lipid content quantitation was carried out by dye elution using isopropanol, and absorbance was measured by spectrophotometer at $500 \mathrm{~nm}$. C.-D. At every time-point, total cell number and dead cell percentage were also measured. *, $p \leq 0.001$; \#, $p \leq 0.01 ; \$, p \leq 0.05$. 

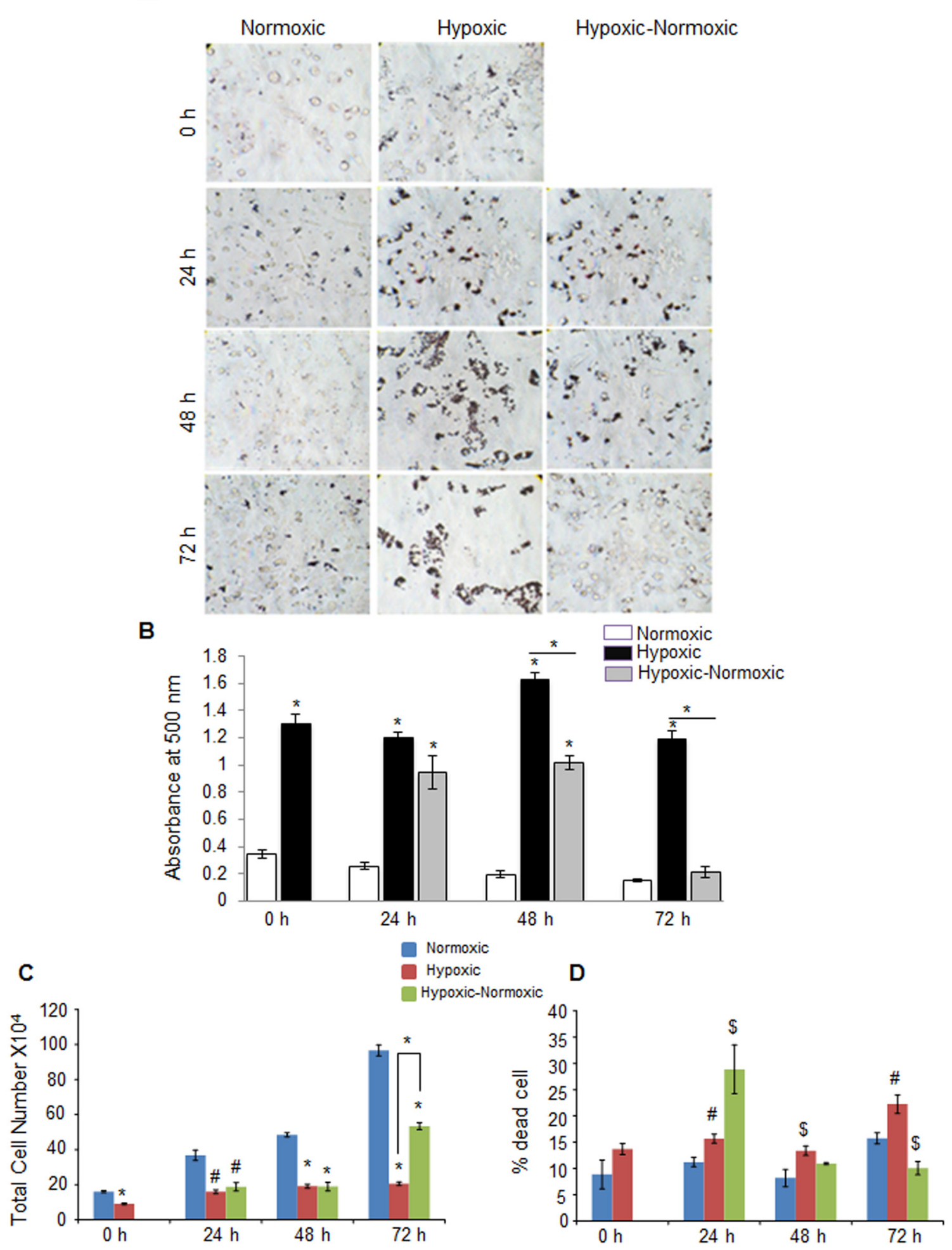

Figure 5: Hypoxia induces lipid accumulation and promotes proliferation following reoxygenation in prostate cancer DU145 cells. DU145 cells were seeded at 50,000 cells/ well in a 6 well plate. After $36 \mathrm{hrs,} \mathrm{media} \mathrm{was} \mathrm{changed} \mathrm{and} \mathrm{cells} \mathrm{were} \mathrm{either}$ transferred to hypoxia chamber $\left(1 \% \mathrm{O}_{2}\right)$ or continued under normoxia $\left(21 \% \mathrm{O}_{2}\right)$. After $48 \mathrm{hrs}$, one set of hypoxic plates was transferred to normoxia and maintained in normoxic conditions for 24,48 and $72 \mathrm{hrs,} \mathrm{while} \mathrm{another} \mathrm{set} \mathrm{remained} \mathrm{under} \mathrm{hypoxia.} \mathrm{A.-B.} \mathrm{After} \mathrm{completing}$ the respective time periods; cells were fixed with $10 \%$ formaldehyde and stained with ORO. Representative pictures (at 200X) for ORO staining are shown. Lipid content quantitation was carried out by dye elution using isopropanol, and absorbance was measured by spectrophotometer at $500 \mathrm{~nm}$. C.-D. At every time-point, total cell number and dead cell percentage were also measured. *, $p \leq 0.001$; \#, $p \leq 0.01 ; \$, p \leq 0.05$. 


\section{Inhibition of lipid $\beta$-oxidation compromised the cell growth following reoxygenation in hypoxic LNCaP cells}

As mentioned above, we observed a striking inverse correlation between reoxygenation and cellular lipid content in the PCA cells. This led us to speculate that the accumulation of lipids during hypoxic conditions allows cells to survive in a cytostatic state until reoxygenation. Upon reoxygenation, these cells could break down the stored lipids by $\beta$-oxidation, and use the energy to proliferate. This notion is supported by studies claiming that, under hypoxic conditions, $\beta$-oxidation is inhibited, and a recent report suggested that CPT1 and ACSL1, which facilitate fatty acid import and oxidation, respectively, were both suppressed by activation of HIF2 $\alpha$ in liver-specific VHL-knockout mouse model [27]. Hence, we decided to use a synthetic $\beta$-oxidation inhibitor, etomoxir, to target the growth of these tumor cells upon reoxygenation. Under normoxic conditions, treatment of $\mathrm{LNCaP}$ cells with etomoxir did not result in any cytotoxicity (Figure 6A and 6B). However, we observed a moderate decrease in cell number in hypoxic condition $(17.6 \% ; p<0.01)$, but in the case of hypoxicnormoxic cells, the number decreased by $28 \%(p<0.001)$, suggesting that fatty acid oxidation plays an important for sustained growth during reoxygenation (Figure 6A-6B).

It is also known that $\beta$-oxidation is a major source for intracellular ROS generation [28]. Thus, we anticipated that the reoxygenated cells would show higher amount of intracellular ROS production. We found that under normoxic and hypoxic condition, less than $10 \%$ of the cells were ROS positive, but with reoxygenation, there was a drastic increase in the ROS positive population $(49.7 \% ; p<0.001)$ (Figure 6C). Addition of etomoxir during reoxygenation completely reversed this, with only 9.7\% cells positive for ROS (Figure 6C).

Additionally, we found a significant increase (48\%) in lipid accumulation with etomoxir treatment in $\mathrm{LNCaP}$ cells under normoxic condition (Figure 6D and 6E). As expected, under hypoxic conditions, etomoxir treatment did not lead to any change in lipid accumulation, as $\beta$-oxidation is already inhibited under these conditions (Figure 6D and 6E). With reoxygenation, addition of etomoxir led to $17 \%$ increase in lipid compared to hypoxic-normoxic control (Figure 6D and 6E).

To further verify the role of $\beta$-oxidation in the reoxygenation-induced growth, we used LNCaP CPT1 knocked down (KD) cells under different oxygen conditions. We have reported earlier that LNCaP-CPT1$\mathrm{KD}$ cells have a $60 \%$ decrease in $\beta$-oxidation [29]. As expected, in $\mathrm{LNCaP}$ vector control (VC) cells, hypoxia caused a $40 \%$ decrease in cell number, but in hypoxicnormoxic conditions, the cell number significantly increased (Figure 7A). However, in the LNCaP-CPT1-KD cells, hypoxia exposure resulted in only a slight decrease $(\sim 12 \%)$ in cell number, and no significant increase in proliferation was observed following reoxygenation of hypoxic cells (Figure 7A). The molecular mechanism responsible for relatively better survival of LNCaP-CPT1$\mathrm{KD}$ cells compared to $\mathrm{LNCaP}-\mathrm{VC}$ cells under hypoxic conditions is unknown, but could be attributed to higher anaerobic glycolysis, as these cells have shown increased uptake of glucose compared to control cells (VC) [30]. Alternatively, the better survival of LNCaP-CPT1-KD could be due to decreased intracellular ROS generation associated with lower $\beta$-oxidation in these cells. Further, as expected, LNCaP-CPT1-KD cells did not show any lipid accumulation under hypoxic conditions compared to normoxic conditions, and compared to vector control cells, showed increased lipid accumulation following reoxygenation, confirming an impediment in the $\beta$-oxidation pathway (Figure 7B and 7C).

\section{Celecoxib blocks hypoxia-mediated clonogenicity of PCA cells}

As mentioned above, we observed increased levels of arachidonic acid (AA) and linoleic acid (AA precursor) in PCA cells exposed to hypoxia. It is known that metabolism of these lipids through oxygenases (such as COX2) generates potent signaling molecules that promote cell proliferation and invasiveness [31-33]. Therefore, we next examined the effect of the COX2 inhibitor, celecoxib, on the clonogenicity of $\mathrm{LNCaP}$ and $22 \mathrm{Rv} 1$ cells exposed to hypoxia for 2 days. Figure $8 \mathrm{~A}$ shows that addition of 10 $\mu \mathrm{M}$ celecoxib to cells resulted in $75 \%(\mathrm{p} \leq 0.001)$ decrease in colony formation in normoxia, and $80 \%(\mathrm{p} \leq 0.001)$ decrease in clonogenicity under hypoxia. At the $25 \mu \mathrm{M}$ celecoxib dose, the hypoxia-treated cells did not form any colonies but a few clones were observed under normoxia (Figure 8A). The 22Rv1 cells showed the same pattern as $\mathrm{LNCaP}$ cells (Figure $8 \mathrm{~B}$ ). These results suggested the importance of COX2 enzymatic products in the growth of reoxygenated PCA cells.

\section{Celecoxib blocks the hypoxia-mediated invasive behavior of $\mathrm{LNCaP}$ cells}

Next, we examined whether the accumulated lipids in LNCaP cells under hypoxic conditions are also involved in invasiveness. We exposed the $\mathrm{LNCaP}$ cells to hypoxic conditions for $48 \mathrm{hrs}$, a time-point by which these cells accumulate lipids. Next, we collected these cells and examined their invasiveness in the presence of celecoxib. As shown in Figure 8C, hypoxia exposure significantly increased the invasive cell population, which was abrogated by celecoxib treatment, suggesting that the invasive phenotype due to the hypoxia is likely mediated 
A
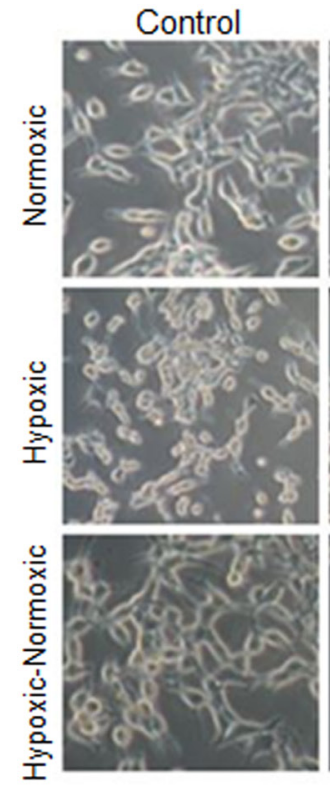

C
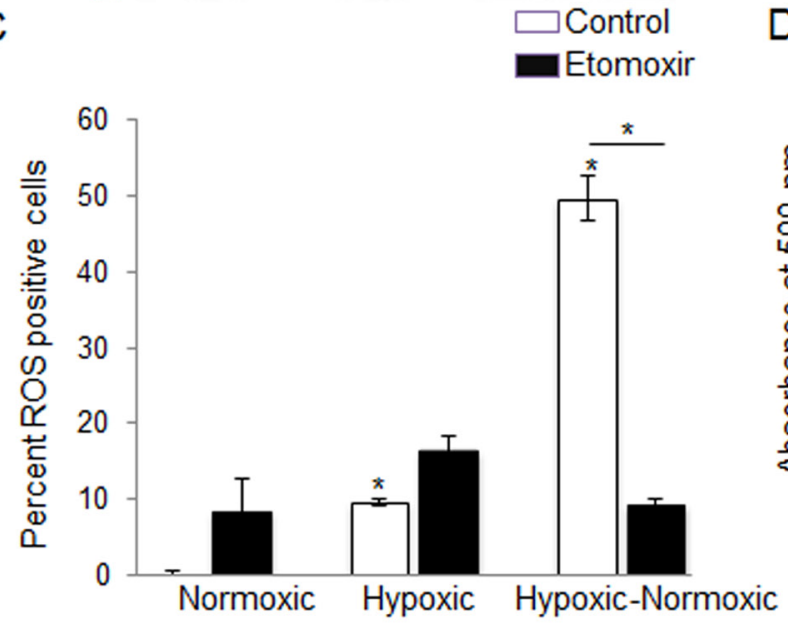

B
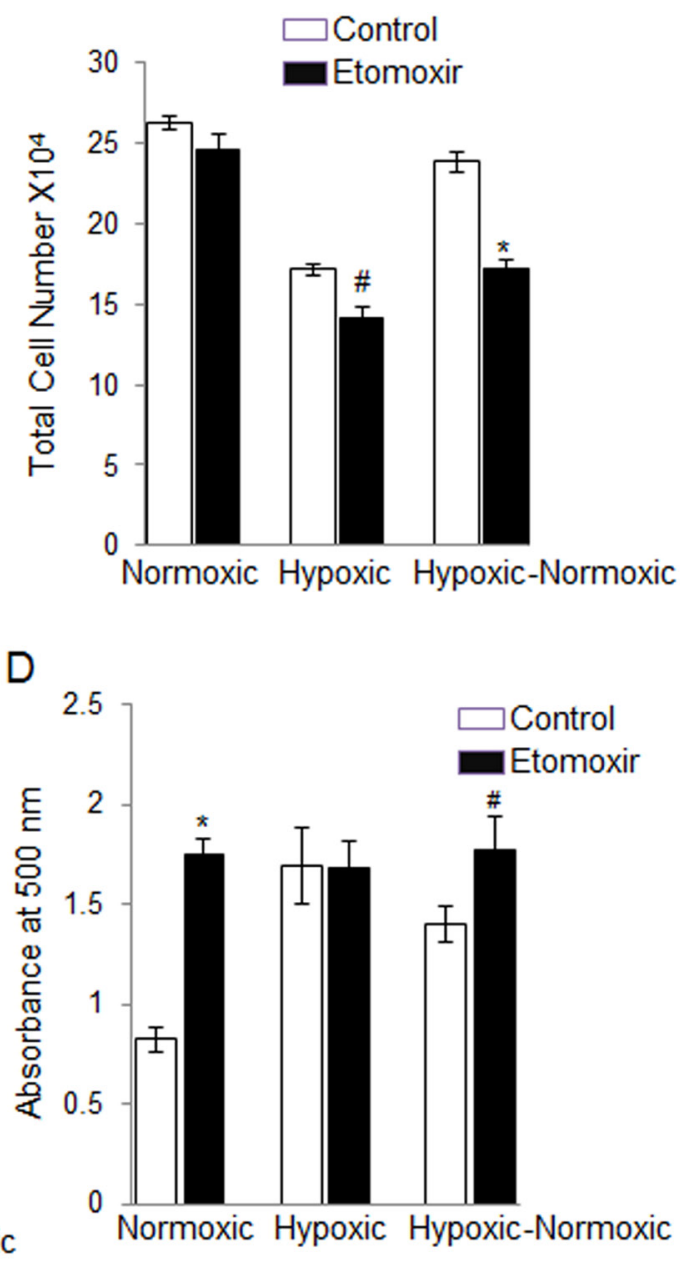

E

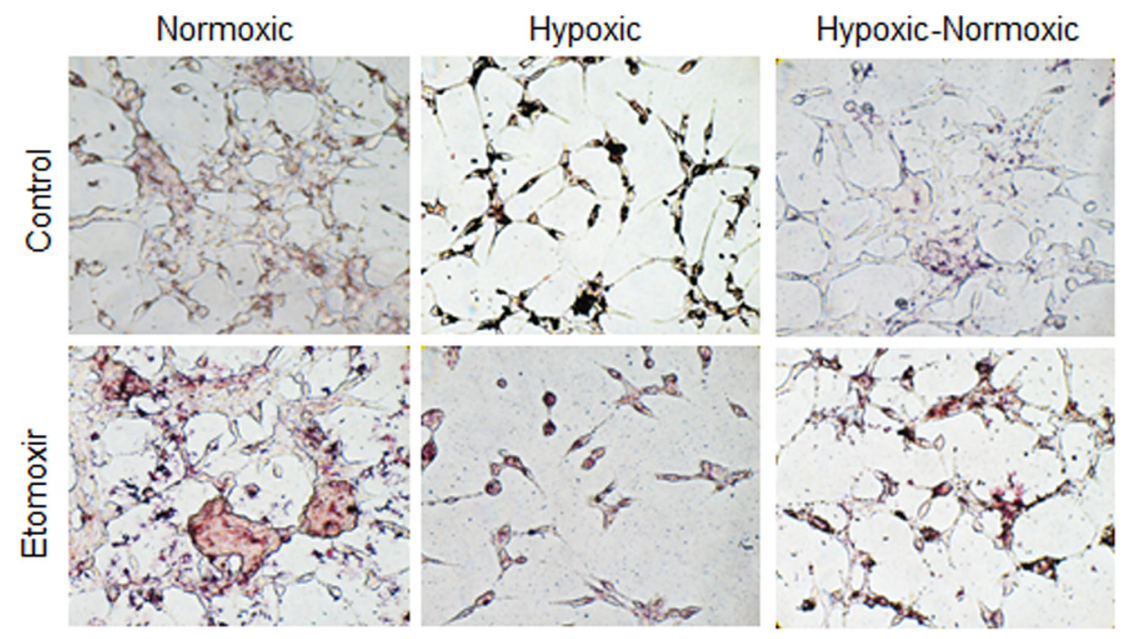

Figure 6: Inhibition of lipid $\beta$-oxidation by etomoxir decreases cell growth following reoxygenation in hypoxic LNCaP cells. LNCaP cells were seeded at 50,000 cells/ well in a 6 well plate. After $36 \mathrm{hrs,} \mathrm{media} \mathrm{was} \mathrm{changed} \mathrm{and} \mathrm{cells} \mathrm{were} \mathrm{either} \mathrm{transferred} \mathrm{to}$ the hypoxia chamber $\left(1 \% \mathrm{O}_{2}\right)$ or continued in normoxia $\left(21 \% \mathrm{O}_{2}\right)$. After $48 \mathrm{hrs}$, one set of hypoxic plates was transferred to normoxia, while another set remained under hypoxic conditions. All the groups (normoxic, hypoxic and hypoxic-normoxic) were treated with etomoxir. After 24 hrs of etomoxir treatment, A. images were captured for cell morphology; B. total cell number was measured; C. ROS level was measured by flow cytometry as detailed in the methods; and D.-E. lipid content was measured via ORO staining and quantified; and representative pictures (at 200X) for ORO staining are shown. *, $p \leq 0.001$; $\#, p \leq 0.01$. 


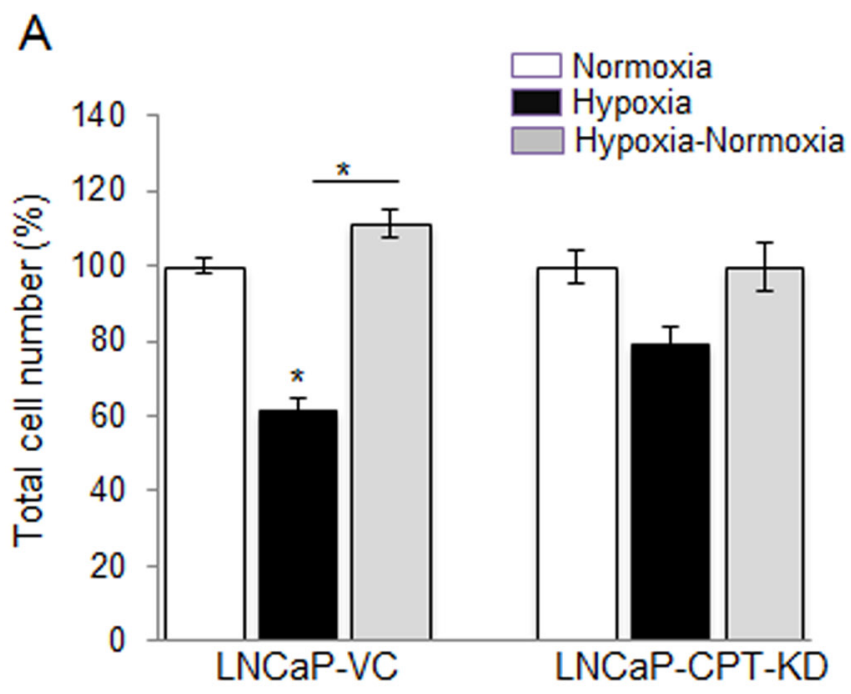

B

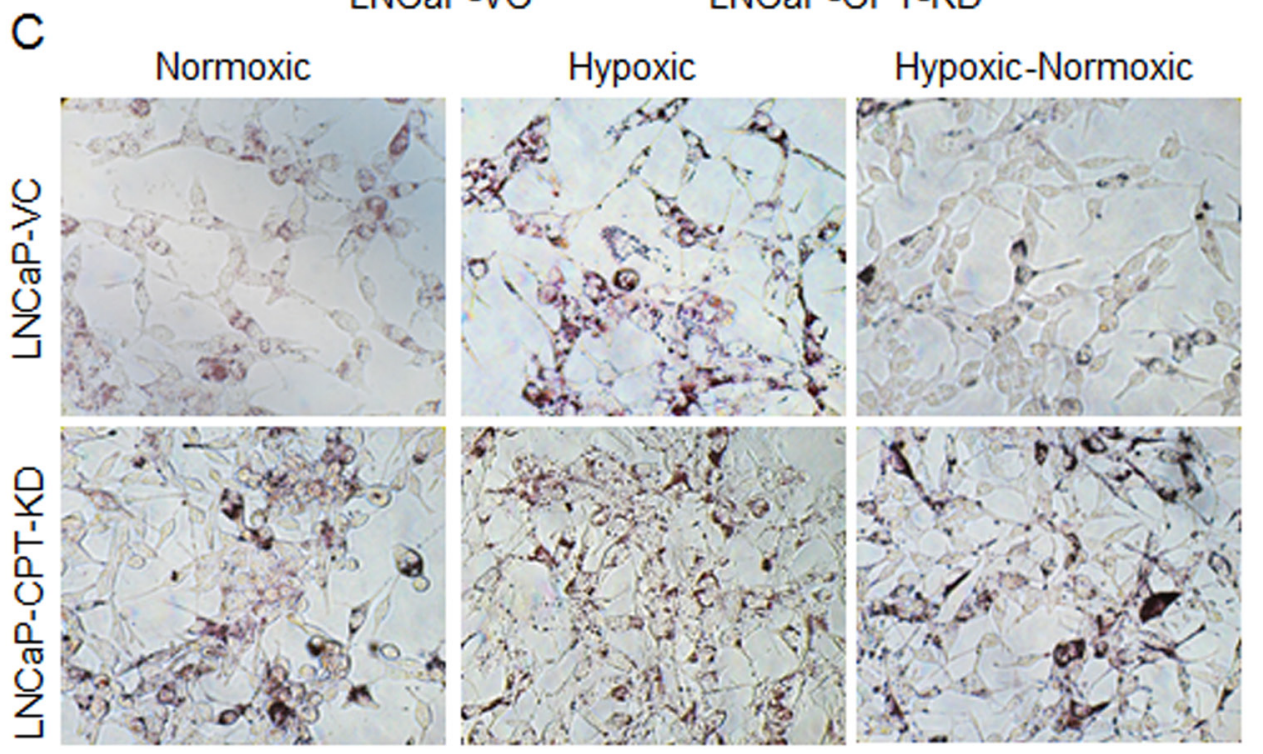

Figure 7: CPT1 knock-down compromised cell growth due to lack of lipid use following reoxygenation in hypoxic LNCaP cells. LNCaP-VC and LNCaP-CPT-KD cells were seeded at 50,000 cells/ well in a 6 well plate. After 36 hrs, media was changed and cells were either transferred to the hypoxia chamber $\left(1 \% \mathrm{O}_{2}\right)$ or continued in normoxia $\left(21 \% \mathrm{O}_{2}\right)$. After $48 \mathrm{hrs}$, one set of hypoxic plates was transferred to normoxia, and $24 \mathrm{hrs}$ later $\mathbf{A}$. total cell number was counted and presented as percentage relative to $100 \%$ normoxic control cells; B.-C. lipid content was measured via ORO staining and quantified; and representative pictures (at 200X) for ORO staining are shown. * $p \leq 0.001$. 
by arachidonic acid-derived metabolites via COX2 activity. Similarly, EVs collected from hypoxic LNCaP cells $\left(\mathrm{EV}^{\text {Hypoxic }}\right)$ increased the invasiveness of LNCaP cells (1.7 fold) compared to EVs collected from normoxic LNCaP cells (EV ${ }^{\text {Normoxic }}$ ) (Figure 8D). More importantly, celecoxib treatment significantly reduced the $\mathrm{EV}^{\text {Hypoxic }}$ induced invasiveness in LNCaP cells (Figure 8D) further highlighting the role of COX enzymes and arachidonic acid-derived metabolites.

\section{Lipids are important for EVs synthesis and loading}

Next, we tested whether cellular lipid levels are crucial for EV biosynthesis and loading. LNCaP cells were cultured under FBS or delipidized serum in the presence of lipogenesis inhibitors fatostatin (FS) and silibinin [34]. As shown in Figure 9A and 9B, LNCaP cells under delipidized serum condition secreted significant lesser amount of EVs under both normoxic and hypoxic condition, and also resulted in a significant decrease in VEGF loading in the EVs. Since PCA cells could
A

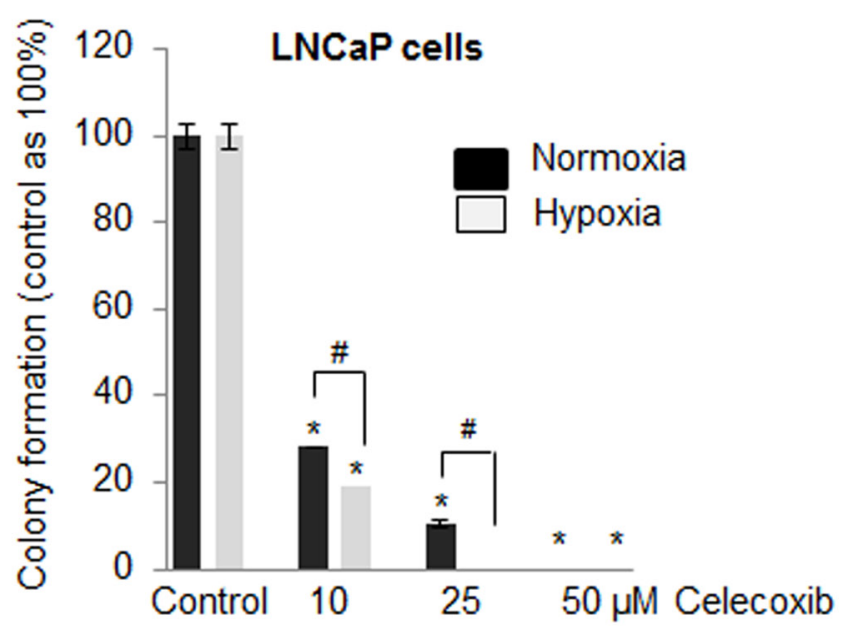

B
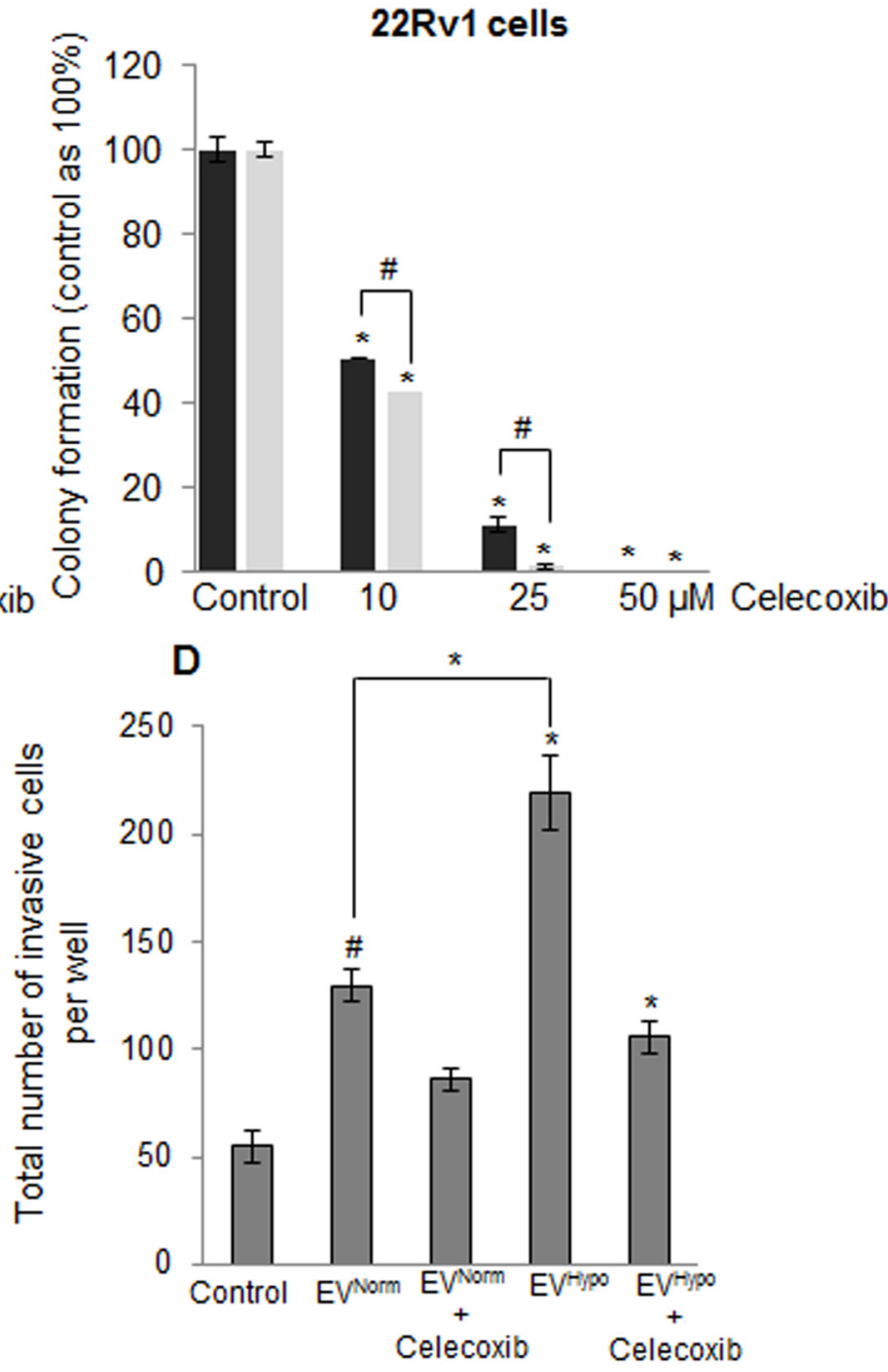

Figure 8: Increased sensitivity of hypoxia-exposed PCA cells towards celecoxib following reoxygenation. A. LNCaP and B. $22 \mathrm{Rv} 1$ cells were exposed to hypoxia for $48 \mathrm{hrs}$ and returned to normoxia with or without celecoxib for 6 days. Clones were counted as detailed in the methods and presented as percentage of control. C. LNCaP cells were exposed to normoxic or hypoxic conditions for 48 hrs; thereafter cells were collected and analyzed for invasiveness in the presence or absence of celecoxib (25 $\mu \mathrm{M})$. After $22 \mathrm{hrs}$, number of invasive cells was determined for each group as detailed in the methods. D. EV ${ }^{\text {Normoxic }}$ and $\mathrm{EV}^{\text {Hypoxic }}$ were collected from LNCaP cells as detailed in methods. Thereafter, naïve LNCaP cells (100,000 cells per well) were incubated along with $25 \mu \mathrm{g}$ of EV ${ }^{\text {Normoxic }}$ or EV Hypoxic in the presence or absence of celecoxib $(25 \mu \mathrm{M})$ and invasiveness was measured after $22 \mathrm{hrs}^{*}, p \leq 0.001 ; \#, p \leq 0.01 ; \$, p \leq 0.05$. 
synthesize lipids under low external lipid conditions, we also treated cells with lipogenesis inhibitor FS or silibinin. As shown in the Figure 9A and 9B, silibinin but not FS showed additional decrease in EV concentration as well as VEGF loading, probably due to its paninhibitory effects on lipogenesis [34] compared to the more specific inhibition of SREBP $1 / 2$ by FS. Also, we observed relatively higher VEGF loading in EVs by FS treatment especially under normoxic conditions (Figure 9A); the reason and mechanism responsible for that need further examination. Importantly, we did not observe any significant change in the mean EV sizes in any of the group (Figure 9C).



Figure 9: $\mathbf{E V}^{\text {Normoxic }}$ or $\mathbf{E V}^{\text {Hypoxic }}$ concentration and loading is compromised in LNCaP cells cultured under reduced lipid conditions and in the presence of lipogenesis inhibitors. LNCaP cells were cultured under normoxic and hypoxic conditions either under 10\% FBS or delipidized 10\%FBS conditions in the presence of fatostatin $(10 \mu \mathrm{M})$ and silibinin $(100 \mu \mathrm{M})$. Under each treatment condition, EVs were isolated and analyzed for A. VEGF loading by immunoblotting and B.-C. concentration (number/ml) and mean size by NTA. 


\section{DISCUSSION}

Hypoxia is a major contributor to tumor growth and its aggressiveness. Typically, hypoxia is detrimental and unfavorable for cell proliferation but cancer cells survive even in harsh hypoxic conditions. The means by which cancer cells adapt to these conditions and sustain their growth remain largely unknown. Previous studies from our lab have identified unique sets of proteins that are loaded in hypoxic PCA EVs and could be responsible for the enhanced invasiveness, stemness and microenvironment changes in PCA cells [2]. The key findings of the present study are: a) under hypoxic conditions, specific lipid moieties are accumulated in PCA cells and their EVs; b) accumulated lipids play an important role in the growth and invasiveness of hypoxic PCA cells following reoxygenation; and c) hypoxia- induced aggressiveness (growth and invasiveness) could be compromised via targeting arachidonic acid pathway as well as the lipogenesis and lipid catabolism pathways (Figure 10).

The accumulation of lipids in cells and their EVs under hypoxia is likely derived by the de novo synthesis of lipids using glucose carbons from the media. This is corroborated by the fact that ACLY and ACSL1 are upregulated during hypoxia, while the acetate-derived lipid synthesis via AceCS1 does not seem to play a role in hypoxia [35]. These results are also in line with earlier reports, which showed hypoxia-stimulated lipid storage and attenuated lipolysis in cardiomyocytes and macrophages [36, 37]. An increase in lipogenesis is also well documented in cancer cells especially in PCA cells $[38,39]$; although no prior study has examined the triglyceride accumulation in EVs from hypoxic PCA cells.

\section{PCA cells under hypoxic conditions}



Figure 10: Hypoxia induces PCA aggressiveness via enhancing lipid accumulation in cells and EVs. Proposed model suggesting that under hypoxic condition lipids are accumulated in cells as well as loaded in EVs. Specific lipid moieties are used as energy sources as well as cues for higher growth and invasiveness when hypoxic cells are reoxygenated, or when normoxic cells receive $\mathrm{EV}^{\mathrm{Hyp} p \mathrm{xic}}$. These hypoxia-induced aggressive features could be targeted by drugs such as fatostatin, silibinin, etomoxir and celecoxib. 
Prostate tumors are known to import more fat than glucose compared to other tumors [34, 40]. Hence $\beta$-oxidation of lipids is considered an important alternative energy source [41]. Our results implicate the role of lipid catabolism ( $\beta$-oxidation) in the growth of hypoxic PCA cells especially following reoxygenation. This is important since targeting the ability of cells to burn the lipid is likely a therapeutic window to treat the refractory hypoxic areas of tumors that get exposed to oxygen, like post-surgery or after radiation treatments. Additionally, lipogenesis inhibitors that limit the accumulation of lipid droplets (like silibinin) could synergize with fat burning inhibitors (like etomoxir) to limit the production of substrate available for oxidation. However, further specific tracer studies (using labelled glucose or fatty acids) are required to track the fate of lipids accumulated under hypoxia, helping elucidate if the lipids are used as an energy source and/or for membrane synthesis for growth.

Several lipids such as BMP (bismonoacylglycerolphosphate), ceramides, cholesterol etc have been reported to play important role in exosome/ EV biogenesis and loading [42]. The present study further highlights the role of cellular lipids in the biogenesis of EVs, as concentration of EVs as well as VEGF loading decreased significantly under delipidized serum condition. Moreover, the lipogenesis inhibitor silibinin significantly reduced the EV concentration as well as VEGF loading. These results suggest that EV synthesis as well as EVregulated signaling in the tumor microenvironment could be targeted by decreasing lipid delivery (via hypolipidemic drugs) as well as reducing the ability of tumors to synthesize lipid (via fatostatin or silibinin) (Figure 10). However, more definite studies are warranted to understand the molecular mechanism underlying the loading of bioactive lipids in EVs especially under hypoxia.

EVs offer a great source of bioactive lipids once they arrive to their final destination ('recipient cells') and are processed. Lipids transported by EVs could be delivered to various cytosolic proteins like lipases for triglycerides breakdown. For example, palmitic and oleic fatty acids delivered by hypoxic EVs could be used to generate more phospholipids for membrane synthesis or used as fuel in the mitochondria to generate ATP if the recipient cells is oxygenated (which is the case in the periphery or margins of the tumors). Similarly, other fatty acids transported by EVs, like arachidonic acid can be delivered to enzymes located on intracellular membranes and allow the production of bioactive lipid molecules (eicosanoids) that could enhance growth and motility of the recipient cell. Through these mechanisms, hypoxic PCA EVs could enhance the overall aggressiveness of the tumor mass.

The role of the linoleic acid and its derivative arachidonic acid in the growth and invasive phenotype of PCA is an active area of research. These lipids are substrates for oxygenases (like COX1, COX2 and lipoxygenases) that transform arachidonic acid into potent lipid signaling molecules including prostaglandins, leukotrienes, and hydroxylated forms of arachidonic acid. Our results indicate that hypoxia promotes shunting of arachidonic acid to lipid droplets or triglyceride stores inside cells and EVs, generating a powerful reserve of signaling metabolites. In fact, using the COX inhibitor celecoxib, we were able to decrease the clonogenic and invasive potential of PCA cells that were exposed to hypoxia. We also observed that $\mathrm{EVs}^{\text {Hypoxic-induced }}$ invasiveness is significantly compromised in the presence of celecoxib, suggesting the key role of arachidonic acid metabolites in $\mathrm{EVs}^{\text {Hypoxic }}$-mediated invasiveness. These results suggest a role for arachidonic acid accumulation in triglycerides during hypoxia that can be used later on when the cells/EVs are re-exposed to oxygen and the COX enzymes are functional. These findings offer further support to therapeutic options based upon targeting the metabolism of bioactive lipids.

Androgen and androgen receptor (AR) signaling play key roles in PCA growth and progression. In fact, androgen ablation (surgical and/or chemical castration) is a key component of PCA therapy. Importantly, androgen ablation by castration induces hypoxia caused by reduced blood flow to the prostate tissue $[43,44]$. Similarly, antiandrogen casodex treatment increased the expression of hypoxia signature genes in LNCaP cells [45]. Mitani et al. reported that hypoxia enhances AR transcriptional activity under low androgen conditions, mimicking the androgen independence stage [46]. We have previously reported that transcriptional regulators of lipogenesis (SREBP1/2) play important role in achieving androgen-independent growth in LNCaP cells [34]. Results from the present study suggest that hypoxia promotes lipid accumulation in PCA cells independent of their AR status as we observed similar results in three different PCA cell lines- androgendependent $\mathrm{LNCaP}$ cells with functional androgen receptor (AR), androgen-independent $\mathrm{C} 4-2 \mathrm{~B}$ cells with functional AR and androgen-independent DU145 cells lacking functional AR. Together, these studies suggest that there is an intricate connection between hypoxia, androgen-AR signaling and lipogenesis, but more studies are needed to understand the key molecular mechanism for lipid accumulation under hypoxic conditions and whether hypoxia promotes androgen-independent PCA growth through enhancing lipogenesis and androgen biogenesis.

Altogether, our results show that hypoxia in PCA cells induces a signaling profile conducive to the generation of lipid synthesis and storage, a phenotype that is also reflected in the EVs they produce. The molecular lipid signature of PCA cells and their EVs may serve as a biomarker to assess the oxygenation status and aggressiveness of malignant tumors. Targeting the machinery that generates triglyceride-loaded EVs and/or the lipid-processing enzymes of the recipient cells offers 
potential therapeutic opportunities against PCA for the future.

\section{MATERIALS AND METHODS}

\section{Cell lines and reagents}

Human PCA LNCaP, DU145, 22Rv1, and C4-2B cells were purchased from ATCC (Manassas, VA). LNCaPvehicle control (LNCaP-VC) and CPT-knockdown cells (LNCaP-CPT-KD) were earlier generated with Sigma TRCN0000036279 (CPT-KD) and the non-targeting control SHC002 purchased from the Functional Genomics Core (Boulder, CO) [30]. Preparation of the lentiviral particles was done as described [29]. RPMI1640 medium and other cell culture materials were from Invitrogen Corporation (Gaithersburg, MD). Delipidized fetal bovine serum was from Gemini Bio-products (West Sacramento, CA). ExoQuick ${ }^{\mathrm{TM}}$ and exosome-free FBS (Exo-FBS ${ }^{\mathrm{TM}}$ ) were from System Biosciences (Mountain View, CA). Antibodies for HIF1 $\alpha$, HIF1 $\beta$, phosphorylated and/or total ACC, ACLY, hexokinase (I and II), PKM2, FASN, ACSL1, AceCS1, SCD1, mTOR, Akt, AMPK, and antirabbit peroxidase-conjugated secondary antibody were from Cell Signaling (Beverly, MA). Antibody for $\alpha$-tubulin was from Lab Vision Corporation (Fremont, CA). ECL (Enhanced Chemiluminescence) detection system and anti-mouse HRP-conjugated secondary antibody were from GE Healthcare (Buckinghamshire, UK). Etomoxir, celecoxib, fatostatin and silibinin were from Sigma (St Louis, MO). All other reagents were obtained in their commercially available highest purity grade.

\section{Cell culture and hypoxia exposure}

LNCaP, C4-2B, and 22Rv1 cells were cultured at $37^{\circ} \mathrm{C}$ in a $5 \% \mathrm{CO} 2$ humidified environment as adherent monolayer in RPMI1640 medium supplemented with $10 \%$ fetal bovine serum (FBS) and $100 \mathrm{U} / \mathrm{ml}$ penicillin $\mathrm{G}$ and $100 \mu \mathrm{g} / \mathrm{ml}$ streptomycin sulfate. DU145 cells were cultured similarly, however 10\% heat-inactivated FBS was used. LNCaP-VC and LNCaP-CPT-KD cells were cultured in LNCaP media with puromycin $(1 \mu \mathrm{g} / \mathrm{ml})$. Hypoxia experiments were performed using a hypoxia chamber from Biospherix (Lacona, NY) at $1 \% \mathrm{O}_{2}$ at $37^{\circ} \mathrm{C}$ in a $5 \% \mathrm{CO}_{2}$ humidified environment. For EVs isolation, LNCaP cells were cultured in media supplemented with exosome-depleted FBS. Exosomes were depleted from delipidized FBS by ultracentrifugation at 30,000 rpm for 2 hrs similar to as described below.

\section{EV isolation}

EVs were isolated from the conditioned media following our earlier published method [2]. Briefly, LNCaP cells were cultured for $48 \mathrm{hrs;}$ thereafter, media was replaced with RPMI1640 supplemented with $10 \%$ exosome-depleted FBS and cultured under normoxic $\left(21 \% \mathrm{O}_{2}\right)$ or hypoxic $\left(1 \% \mathrm{O}_{2}\right)$ conditions for 48 hrs. Subsequently, conditioned media was harvested and EVs were isolated by traditional methods using serial centrifugation at low speed, followed by ultracentrifugation (L-80 Ultracentrifuge, Beckman Coulter) at 30,000 rpm using type 70.1 Ti fixed angle rotor (Beckman Coulter). The EVs were also isolated by a precipitation method using commercially available Exoquick $^{\mathrm{TM}}$ reagent (System Biosciences) according to the vendor's instructions. Briefly, conditioned media was overnight incubated with Exoquick ${ }^{\mathrm{TM}}$ reagent, centrifuged at 5,000 rpm for $2 \mathrm{hrs}$ and the pellet was washed once with PBS, and pelleted EVs were resuspended in PBS and stored at $-20^{\circ} \mathrm{C}$ until further use. EVs collected from normoxic and hypoxic PCA cells conditioned media were labelled as $\mathrm{EV}^{\text {Normoxic }}$ and $\mathrm{EV}^{\text {Hypoxic }}$, respectively.

\section{Lipid extraction, fractionation and analysis by gas chromatography-mass spectroscopy (GC-MS)}

LNCaP cells were grown in $10 \mathrm{~cm}$ dishes and exposed to hypoxia for $48 \mathrm{hrs}$. Cells and EVs were resuspended in 1:1 volumes of PBS and methanol and kept at $-80^{\circ} \mathrm{C}$ until ready to use. An aliquot of $100 \mu \mathrm{L}$ was used for cell count using a hemocytometer for cell and EVs normalization. Lipids were extracted using the Bligh and Dyer method [47]. Samples were shaken on a rotational mixer for $1.5 \mathrm{hrs}$ at $4^{\circ} \mathrm{C}$, and then spun at 3,000 $\mathrm{rpm}$ for $15 \mathrm{~min}$ to separate phases. The organic bottom layer was dried down under $\mathrm{N} 2$ at $40^{\circ} \mathrm{C}$, resuspended in chloroform, and added to aminopropyl solid phase extraction (SPE) columns (Supelclean LC-NH2, $3 \mathrm{ml}$, Supelco Analytical). Phospholipids, triglycerides and diacylglycerols were isolated using SPE based on the methods originally described by Kaluzny [48]. Lipid fractions were converted to fatty acid methyl esters (FAME) by transmethylation using sodium methoxide. Concentration and composition analysis were performed on an HP 6890 gas chromatography system with a 30m DB-23 capillary column, connected to a HP 5973 mass spectrometer. Peak identities were determined by retention time and mass spectra compared to standards of known composition. 


\section{Western blotting}

PCA cells grown under normoxic and hypoxic conditions were lysed with lysis buffer $(10 \mathrm{mmol} / \mathrm{L}$ Tris- $\mathrm{HCl}, \mathrm{pH} 7.4,1 \% \mathrm{SDS}$ and $2 \mathrm{mmol} / \mathrm{L}$ sodium orthovanadate), boiled in a water bath for $5 \mathrm{~min}$ and purge with a $271 / 4$ gauge needle. EVs isolated by Exoquick $^{\mathrm{TM}}$ precipitation were lysed with ice-cold RIPA buffer $(25 \mathrm{mM}$ Tris $\bullet \mathrm{HCl} \mathrm{pH} 7.6,150 \mathrm{mM} \mathrm{NaCl}, 1 \% \mathrm{NP}-$ $40,1 \%$ sodium deoxycholate, $0.1 \% \mathrm{SDS}, 0.3 \mathrm{mmol} / \mathrm{L}$ phenylmethylsulfonyl fluoride and 5 units $/ \mathrm{mL}$ aprotinin). The protein concentration of lysates was estimated using Bio-Rad DC protein assay kit (Bio-Rad, Hercules, CA). Samples were subjected to SDS-PAGE on $8-16 \%$ trisglycine gels and blotted onto nitrocellulose membranes. Membranes were probed with specific primary antibodies over-night at $4{ }^{\circ} \mathrm{C}$ followed by peroxidase-conjugated appropriate secondary antibody for $1 \mathrm{hr}$ at room temperature, and visualized by ECL detection system. Membranes were also stripped and re-probed again for protein of interest.

\section{Oil red o (ORO) staining}

At the end of desired treatment, cells were fixed in $10 \%$ buffered formalin for $15 \mathrm{~min}$ at room temperature, washed twice with PBS and then with $60 \%$ isopropanol for $5 \mathrm{~min}$. After isopropanol wash, the plate was completely dried and stained with ORO stain $(0.3 \%$ ORO in $100 \%$ isopropanol, diluted with distilled water in the ratio of 3:2) for $30 \mathrm{~min}$. After staining, cells were washed with distilled water to get a clear background. Pictures were captured at 200X magnification under a microscope and lipid content quantitation was carried out by dye elution using $100 \%$ isopropanol and absorbance was measured by spectrophotometer at $500 \mathrm{~nm}$.

\section{Analysis of ROS levels}

LNCaP cells were seeded at 50,000 cells/ well in a 6 well plate. After 36 hrs, media was changed and cells were either transferred to hypoxia or continued under normoxia. After $48 \mathrm{hrs,}$, cells under hypoxic condition were transferred to normoxia and etomoxir $(150 \mu \mathrm{M})$ was added. After $24 \mathrm{hrs}$, cells were incubated with $10 \mu \mathrm{M}$ DCF-DA for $1 \mathrm{hr}$ at $37^{\circ} \mathrm{C}$. The excess probe was washed off with PBS. The cells were trypsinized, resuspended in PBS and analyzed for DCF fluorescence by flow cytometry.

\section{Clonogenic assay}

PCA cells were seeded in 6-well plates (500 cells/well). After $24 \mathrm{hr}$ of plating, one set of plate was transferred to hypoxic condition $\left(1 \% \mathrm{O}_{2}\right)$, while other set was maintained under normoxia. After $48 \mathrm{hrs}$, the plate under hypoxia was returned to normoxic conditions. Subsequently plates were treated with $0,10,25$ and $50 \mu \mathrm{M}$ of celecoxib and cultured for another 6 days, after which the cells were fixed with ice-cold methanol: glacial acetic acid (3:1) for $10 \mathrm{~min}$; and stained with $1 \%$ crystal violet for $10 \mathrm{~min}$. Number of colonies with greater than 50 cells were counted in each of the treatment group.

\section{Invasion assay}

Invasion assay was performed using matrigel coated trans-well chambers from BD Biosciences (San Jose, CA). LNCaP cells were incubated under normoxic $\left(21 \% \mathrm{O}_{2}\right)$ or hypoxic $\left(1 \% \mathrm{O}_{2}\right)$ conditions for $48 \mathrm{hrs}$. Thereafter, to compare invasiveness, LNCaP cells were collected and seeded in the upper chambers $\left(1 \times 10^{5}\right.$ cells per well) in RPMI medium (with $0.5 \%$ FBS) with or without celecoxib. In this assay, bottom chambers were filled with RPMI medium with $10 \%$ FBS. After $24 \mathrm{hrs}$ of incubation under standard culture conditions, LNCaP cells on top surfaces of the membrane (non-invasive cells) were scraped with cotton swabs and cells on the bottom sides of the membrane (invasive cells) were fixed with cold methanol, stained with hematoxylin/eosin and mounted. Images were captured using Cannon Power Shot A640 camera on Zeiss inverted microscope and invasive cells were counted at 100x. In another experiment, LNCaP cells seeded in the upper chambers $\left(1 \times 10^{5}\right.$ cells per well) in RPMI medium (with $0.5 \% \mathrm{FBS}$ ) with or without $\mathrm{EV}^{\text {Normoxic }}$ and $\mathrm{EV}^{\text {Hypoxic }}(25 \mu \mathrm{g}$ each) and celecoxib $(25 \mu \mathrm{M})$, and their invasiveness was determined as described above.

\section{Nanoparticle tracking analysis (NTA)}

EVs concentration was measured using Nanosight LM10 system (Nanosight Ltd, Navato, CA) equipped with a blue laser $(405 \mathrm{~nm})$. EVs were illuminated by the laser and their movement under Brownian motion was captured for 60 seconds and the video recorded was subjected to NTA using the Nanosight particle tracking software to calculate nanoparticle concentrations and size.

\section{Statistical analysis}

All values are presented as mean $\pm \operatorname{SEM}(n=3)$, unless mentioned otherwise. Differences in parameters between treatments were assessed by ANOVA tests followed by Tukey post-hoc analysis. A $p$ value of $\leq 0.05$ was accepted as statistically significant. 


\section{ACKNOWLEDGMENTS}

This work was supported by DOD award \# W81XWh-12-1-0053 (to GD), NCI K01 grant CA168934 (to IRS), NCI RO1 grant CA102514 (to RA) and DBT, Government of India support as Overseas Associateship (to AR).

\section{CONFLICTS OF INTEREST}

No potential conflict of interest was identified by any of the authors.

\section{Abbreviations}

ACC: Acetyl Co-A carboxylase; AceCS1: Acetyl-CoA synthetase 1; ACLY: ATP-citrate lyase; ACSL: Acyl CoA synthase ligase; AMPK: AMPactivated protein kinase; COX2: Cyclooxygenase 2; CPT1: Carnitine palmitoyltransferase 1; DCF-DA: 2',7' -dichlorofluorescein diacetate; DMSO: Dimethyl sulfoxide; ECL: Enhanced chemiluminescence; EV: Extracellular vesicle; FASN: Fatty acid synthase enzyme; FS: Fatostatin; HIF: Hypoxia inducible factor; mTOR: Mammalian target of rapamycin; NTA: Nanoparticle tracking analysis; ORO: Oil red O; PCA: Prostate cancer; PKM2: Pyruvate kinase 2; SCD1: Stearoyl-CoA desaturase 1; SB: Silibinin; SREBP: Sterol regulatory element binding protein

\section{REFERENCES}

1. Siegel R, Ma J, Zou Z, Jemal A. Cancer statistics, 2014. CA: a cancer journal for clinicians. 2014; 64: 9-29.

2. Ramteke A, Ting H, Agarwal C, Mateen S, Somasagara R, Hussain A, Graner M, Frederick B, Agarwal R, Deep G. Exosomes secreted under hypoxia enhance invasiveness and stemness of prostate cancer cells by targeting adherens junction molecules. Molecular carcinogenesis. 2013;54:554-65.

3. Butterworth KT, McCarthy HO, Devlin A, Ming L, Robson T, McKeown SR, Worthington J. Hypoxia selects for androgen independent LNCaP cells with a more malignant geno- and phenotype. International journal of cancer Journal international du cancer. 2008; 123: 760-768.

4. Ranasinghe WK, Xiao L, Kovac S, Chang M, Michiels C, Bolton D, Shulkes A, Baldwin GS, Patel O. The role of hypoxia-inducible factor lalpha in determining the properties of castrate-resistant prostate cancers. PloS one. 2013; 8: e54251.

5. Dai Y, Bae K, Siemann DW. Impact of hypoxia on the metastatic potential of human prostate cancer cells. International journal of radiation oncology, biology, physics. 2011; 81: 521-528.

6. Tatum JL, Kelloff GJ, Gillies RJ, Arbeit JM, Brown JM, Chao KS, Chapman JD, Eckelman WC, Fyles AW, Giaccia AJ, Hill RP, Koch CJ, Krishna MC, Krohn KA, Lewis JS, Mason RP, et al. Hypoxia: importance in tumor biology, noninvasive measurement by imaging, and value of its measurement in the management of cancer therapy. International journal of radiation biology. 2006; 82: 699757.

7. Carnell DM, Smith RE, Daley FM, Saunders MI, Bentzen SM, Hoskin PJ. An immunohistochemical assessment of hypoxia in prostate carcinoma using pimonidazole: implications for radioresistance. International journal of radiation oncology, biology, physics. 2006; 65: 91-99.

8. Chiche J, Brahimi-Horn MC, Pouyssegur J. Tumour hypoxia induces a metabolic shift causing acidosis: a common feature in cancer. Journal of cellular and molecular medicine. 2010; 14: 771-794.

9. Rocha S. Gene regulation under low oxygen: holding your breath for transcription. Trends in biochemical sciences. 2007; 32: 389-397.

10. Umezu T, Tadokoro H, Azuma K, Yoshizawa S, Ohyashiki $\mathrm{K}$, Ohyashiki JH. Exosomal miR-135b shed from hypoxic multiple myeloma cells enhances angiogenesis by targeting factor-inhibiting HIF-1. Blood. 2014; 124: 3748-3757.

11. Tadokoro H, Umezu T, Ohyashiki K, Hirano T, Ohyashiki JH. Exosomes derived from hypoxic leukemia cells enhance tube formation in endothelial cells. The Journal of biological chemistry. 2013; 288: 34343-34351.

12. Wang T, Gilkes DM, Takano N, Xiang L, Luo W, Bishop CJ, Chaturvedi P, Green JJ, Semenza GL. Hypoxiainducible factors and RAB22A mediate formation of microvesicles that stimulate breast cancer invasion and metastasis. Proceedings of the National Academy of Sciences of the United States of America. 2014; 111: E3234-3242.

13. Azmi AS, Bao B, Sarkar FH. Exosomes in cancer development, metastasis, and drug resistance: a comprehensive review. Cancer metastasis reviews. 2013; 32: 623-642.

14. King HW, Michael MZ, Gleadle JM. Hypoxic enhancement of exosome release by breast cancer cells. BMC cancer. 2012; 12: 421.

15. Sano $S$, Izumi $Y$, Yamaguchi $T$, Yamazaki $T$, Tanaka $M$, Shiota M, Osada-Oka M, Nakamura Y, Wei M, Wanibuchi $\mathrm{H}$, Iwao H, Yoshiyama M. Lipid synthesis is promoted by hypoxic adipocyte-derived exosomes in 3T3-L1 cells. Biochemical and biophysical research communications. 2014; 445: 327-333.

16. Llorente A, Skotland T, Sylvanne T, Kauhanen D, Rog T, Orlowski A, Vattulainen I, Ekroos K, Sandvig K. Molecular lipidomics of exosomes released by PC-3 prostate cancer cells. Biochimica et biophysica acta. 2013; 1831: 1302- 
1309.

17. Bartz R, Zehmer JK, Zhu M, Chen Y, Serrero G, Zhao Y, Liu P. Dynamic activity of lipid droplets: protein phosphorylation and GTP-mediated protein translocation. Journal of proteome research. 2007; 6: 3256-3265.

18. Schlaepfer IR, Hitz CA, Gijon MA, Bergman BC, Eckel RH, Jacobsen BM. Progestin modulates the lipid profile and sensitivity of breast cancer cells to docetaxel. Molecular and cellular endocrinology. 2012; 363: 111-121.

19. Straub BK, Herpel E, Singer S, Zimbelmann R, Breuhahn $\mathrm{K}$, Macher-Goeppinger S, Warth A, Lehmann-Koch J, Longerich T, Heid H, Schirmacher P. Lipid dropletassociated PAT-proteins show frequent and differential expression in neoplastic steatogenesis. Modern pathology : an official journal of the United States and Canadian Academy of Pathology, Inc. 2010; 23: 480-492.

20. Suburu J, Chen YQ. Lipids and prostate cancer. Prostaglandins \& other lipid mediators. 2012; 98: 1-10.

21. Subra C, Grand D, Laulagnier K, Stella A, Lambeau G, Paillasse M, De Medina P, Monsarrat B, Perret B, SilventePoirot S, Poirot M, Record M. Exosomes account for vesicle-mediated transcellular transport of activatable phospholipases and prostaglandins. Journal of lipid research. 2010; 51: 2105-2120.

22. Zhdanov AV, Waters AH, Golubeva AV, Papkovsky DB. Differential contribution of key metabolic substrates and cellular oxygen in HIF signalling. Experimental cell research. 2015; 330: 13-28.

23. Chhipa RR, Wu Y, Ip C. AMPK-mediated autophagy is a survival mechanism in androgen-dependent prostate cancer cells subjected to androgen deprivation and hypoxia. Cellular signalling. 2011; 23: 1466-1472.

24. Scaglia N, Chisholm JW, Igal RA. Inhibition of stearoylCoA desaturase-1 inactivates acetyl-CoA carboxylase and impairs proliferation in cancer cells: role of AMPK. PloS one. 2009; 4: e6812.

25. Williams KJ, Argus JP, Zhu Y, Wilks MQ, Marbois BN, York AG, Kidani Y, Pourzia AL, Akhavan D, Lisiero DN, Komisopoulou E, Henkin AH, Soto H, Chamberlain BT, Vergnes L, Jung ME, et al. An essential requirement for the SCAP/SREBP signaling axis to protect cancer cells from lipotoxicity. Cancer research. 2013; 73: 2850-2862.

26. Filipp FV. Cancer metabolism meets systems biology: Pyruvate kinase isoform PKM2 is a metabolic master regulator. Journal of carcinogenesis. 2013; 12: 14.

27. Rankin EB, Rha J, Selak MA, Unger TL, Keith B, Liu Q, Haase VH. Hypoxia-inducible factor 2 regulates hepatic lipid metabolism. Molecular and cellular biology. 2009; 29: 4527-4538.

28. Schonfeld P, Wieckowski MR, Lebiedzinska M, Wojtczak L. Mitochondrial fatty acid oxidation and oxidative stress: lack of reverse electron transfer-associated production of reactive oxygen species. Biochimica et biophysica acta. 2010; 1797: 929-938.
29. Schlaepfer IR, Rider L, Rodrigues LU, Gijon MA, Pac CT, Romero L, Cimic A, Sirintrapun SJ, Glode LM, Eckel RH, Cramer SD. Lipid catabolism via CPT1 as a therapeutic target for prostate cancer. Molecular cancer therapeutics. 2014; 13: 2361-2371.

30. Schlaepfer IR, Glode LM, Hitz CA, Pac CT, Boyle KE, Maroni P, Deep G, Agarwal R, Lucia SM, Cramer SD, Serkova NJ, Eckel RH. Inhibition of Lipid Oxidation Increases Glucose Metabolism and Enhances 2-Deoxy-2[F]Fluoro-D-Glucose Uptake in Prostate Cancer Mouse Xenografts. Mol Imaging Biol. 2015.

31. Sha W, Olesch C, Hanaka H, Radmark O, Weigert A, Brune B. Necrosis in DU145 prostate cancer spheroids induces COX-2/mPGES-1-derived PGE2 to promote tumor growth and to inhibit $\mathrm{T}$ cell activation. International journal of cancer Journal international du cancer. 2013; 133: 15781588 .

32. Sciarra A, Mariotti G, Salciccia S, Autran Gomez A, Monti S, Toscano V, Di Silverio F. Prostate growth and inflammation. The Journal of steroid biochemistry and molecular biology. 2008; 108: 254-260.

33. Lin DW, Nelson PS. The role of cyclooxygenase-2 inhibition for the prevention and treatment of prostate carcinoma. Clinical prostate cancer. 2003; 2: 119-126.

34. Nambiar DK, Deep G, Singh RP, Agarwal C, Agarwal R. Silibinin inhibits aberrant lipid metabolism, proliferation and emergence of androgen-independence in prostate cancer cells via primarily targeting the sterol response element binding protein 1. Oncotarget. 2014; 5: $10017-$ 10033.

35. Wellen KE, Thompson CB. A two-way street: reciprocal regulation of metabolism and signalling. Nature reviews Molecular cell biology. 2012; 13: 270-276.

36. Huss JM, Levy FH, Kelly DP. Hypoxia inhibits the peroxisome proliferator-activated receptor alpha/retinoid $\mathrm{X}$ receptor gene regulatory pathway in cardiac myocytes: a mechanism for O2-dependent modulation of mitochondrial fatty acid oxidation. The Journal of biological chemistry. 2001; 276: 27605-27612.

37. Bostrom P, Magnusson B, Svensson PA, Wiklund O, Boren J, Carlsson LM, Stahlman M, Olofsson SO, Hulten LM. Hypoxia converts human macrophages into triglycerideloaded foam cells. Arteriosclerosis, thrombosis, and vascular biology. 2006; 26: 1871-1876.

38. Mashima T, Seimiya H, Tsuruo T. De novo fatty-acid synthesis and related pathways as molecular targets for cancer therapy. British journal of cancer. 2009; 100: 13691372.

39. Swinnen JV, Brusselmans K, Verhoeven G. Increased lipogenesis in cancer cells: new players, novel targets. Current opinion in clinical nutrition and metabolic care. 2006; 9: 358-365.

40. Liu Y, Zuckier LS, Ghesani NV. Dominant uptake of fatty acid over glucose by prostate cells: a potential new 
diagnostic and therapeutic approach. Anticancer research. 2010; 30: 369-374.

41. Zha S, Ferdinandusse S, Hicks JL, Denis S, Dunn TA, Wanders RJ, Luo J, De Marzo AM, Isaacs WB. Peroxisomal branched chain fatty acid beta-oxidation pathway is upregulated in prostate cancer. The Prostate. 2005; 63: 316-323.

42. Record M, Carayon K, Poirot M, Silvente-Poirot S. Exosomes as new vesicular lipid transporters involved in cell-cell communication and various pathophysiologies. Biochimica et biophysica acta. 2014; 1841: 108-120.

43. Halin S, Hammarsten P, Wikstrom P, Bergh A. Androgeninsensitive prostate cancer cells transiently respond to castration treatment when growing in an androgendependent prostate environment. The Prostate. 2007; 67: 370-377.

44. Shabsigh A, Ghafar MA, de la Taille A, Burchardt M, Kaplan SA, Anastasiadis AG, Buttyan R. Biomarker analysis demonstrates a hypoxic environment in the castrated rat ventral prostate gland. Journal of cellular biochemistry. 2001; 81: 437-444.

45. Rothermund CA, Gopalakrishnan VK, Eudy JD, Vishwanatha JK. Casodex treatment induces hypoxiarelated gene expression in the $\mathrm{LNCaP}$ prostate cancer progression model. BMC urology. 2005; 5: 5.

46. Mitani T, Yamaji R, Higashimura Y, Harada N, Nakano $\mathrm{Y}$, Inui H. Hypoxia enhances transcriptional activity of androgen receptor through hypoxia-inducible factor-1alpha in a low androgen environment. The Journal of steroid biochemistry and molecular biology. 2011; 123: 58-64.

47. Bligh EG, Dyer WJ. A rapid method of total lipid extraction and purification. Canadian journal of biochemistry and physiology. 1959; 37: 911-917.

48. Kaluzny MA, Duncan LA, Merritt MV, Epps DE. Rapid separation of lipid classes in high yield and purity using bonded phase columns. Journal of lipid research. 1985; 26: 135-140. 